\title{
Synthesis of Biodegradable Aloevera-acrylic Acid Based Hydrogel With Enhanced Water Retention Capacity and Its Impact on Agriculture
}

suruchi sharma ( $\sim$ suruchinitj15@gmail.com )

DAV University, Jalandhar

\section{Vaneet Kumar}

CT Group of Institutions

\section{Research Article}

Keywords: Aloe vera, Acrylic acid, Hydrogel, Biodegradation, Water retention

Posted Date: April 14th, 2021

DOl: https://doi.org/10.21203/rs.3.rs-387765/v1

License: (c) (1) This work is licensed under a Creative Commons Attribution 4.0 International License.

Read Full License 
1 Synthesis of Biodegradable Aloevera-acrylic acid based hydrogel with enhanced water retention capacity and its impact on agriculture

Saruchi and Vaneet Kumar

4 Saruchi $^{1 *}$ and Vaneet Kumar ${ }^{3}$

$5 \quad{ }^{1}$ Department of Biotechnology, CT Institute of Pharmaceutical Sciences, Shahpur Campus Jalandhar, Punjab,

6 India

$7 \quad{ }^{2}$ Department of Applied Sciences, CT Institute of Engineering, Management and Technology, Shahpur

8 Campus Jalandhar, Punjab, India

10 Corresponding Author:

11 Dr Saruchi

12 Associate Professor

13 CT Institute of Pharmaceutical Sciences, Jalandhar, Punjab, India

14 saruchi.1378@ctgroup.in

15 Suruchinitj15@gmail.com

\section{Abstract}

The present work deals with the synthesis of biodegradable hydrogel using a natural polysaccharide Aloevera and vinyl monomer acrylic acid. In this synthesis, ammonium per sulphate was used as an initiator and glutaraldehyde as cross-linker, acrylic acid was used as monomers and Aloevera as backbone. Grafting was confirmed by different techniques like SEM, FT-IR, XRD and EDS. Maximum percentage swelling of synthesized hydrogel was found to be $796 \%$. Biodegradation behavior of Av-cl-poly(AA) was studied by soil burial, compositing and vermicompositing method. Maximum biodegradation was found to be $90 \%$, 94\% and $93 \%$ in case of soil burial, composting and vermicomposting methods, respectively. Biodegradation of Av-cl-poly(AA) was confirmed by FTIR and SEM techniques. Water retention capacity was prolonged from 11days to 20 days using synthesized Av-cl-poly(AA). Water content of clay soil and sandy loam soil was increased to an extent of $6.1 \%$ and $5.79 \%$, respectively.

Keywords: Aloe vera, Acrylic acid; Hydrogel; Biodegradation; Water retention

\section{Introduction}

Polymeric materials are designed and chemically transformed displayed appropriate 
properties. They are bio-compatible and bio-degradable in nature and they also substantiate the outline of the surface to which they are implemented. They are also called as 'smart' or 'intelligent' gels, because they have the property of changing its behavior depending on the outer environment. The cross-linkage make the grafting insoluble in a solvent owing to electrostatic interaction and the hydrogen bonding strengthen the polymer.

Properties of the hydrogel to attained large amount of water, controlled release of fertilizers and change its behavior with environmental change, attained the attention of the researchers to use hydrogel as a solution of agricultural problems, without affecting the environment and fertility of soil. Synthesized polymers was employed to increase efficacy of the pesticides and herbicides, permiting lesser dose to be used, which ultimately plays an important role to reduce pollution and protects our eco system (Ekebafe et al., 2011).

Hydrogels used in agriculture field also increase the porosity of the soil by holding large amount of water for a prolonged period of time, which reduced the need of irrigation, lower the erosion of soil and thus increase the fertility of soil. (Choudhary et al., 2014). Hydrogel help in controlled release of agrochemicals, which is very necessary for achieving their impactive usage and also reduced the pollution. Alemzadeh and Vossoughi (2002) prepared hydrogel based on PVA and glutaraldehyde which was later immersed in paraquat solution. The quantity of herbicide sorbed by hydrogel was determined. Kulkarnia et al. (2000) encapsulated natural liquid pesticide neem seed oil, utilising sodium alginate and glutaraldehyde and the swelling studies revealed insignificant disparity in swelling by stocking variable quantity of neem seed oil.

The compatibility of silver coated hydrogels was verified and this system was also used to functionalise polyacrylate hydrogel. The synthesized hydrogels possessed an outstanding water-retention ability which was quite beneficial in rain fed agriculture (Vundavalli et al., 2015). Rabat et al. (2016) synthesized hydrogel from acrylic acid, urea, N,N'-Methylene bis acrylamide (MBA) and ammonium per sulphate (APS) at $70^{\circ} \mathrm{C}$ in the presence of $\mathrm{N}_{2}$ atmosphere. During synthesis, the reaction mixture was neutralised with $\mathrm{NaOH}$, due to which the electrostatic repulsions occurring between carboxylate ions increased, this leads to the expansion of the structure, thereby increasing the water absorption capacity. A super absorbing hydrogel was synthesized using polyacrylic acid with help of polymerisation method. Acetone and sodium bicarbonate were taken as porogens. MBA and 1, 4butanedioldiacrylate was taken as cross-linking agents. 
A super absorbing hydrogel with controlled nitrogen release was synthesized with chemical method, using acrylic acid, potassium per sulphate (KPS) and MBA. Its water absorption capacity was studied by orthogonal experiment. Swelling behavior of the sample was evaluated with distilled and saline water. The results demonstrated good absorption properties and slow release of nitrogen by the sample (Cheng et al., 2018).

The botanical name of Aloevera is Aloe barbadensis. It is a perennial succulent plant belonging to liliace family. It is also named as a healing plant or a silent healer. It is grown not only for agricultural purposes but also for medicinal use. The main components present in it are amino acid, enzyme, lecithin, lipid, minerals, lactates, salicylate, vitamins etc. There are 20 types of amino acids present in aloevera.

The present work deals with the grafting of natural polysaccharide Aloe vera with acrylic acid and monomer using ammonium per sulphate as an initiator and glutaraldehyde as crosslinker. Utilization off synthesized hydrogel for water retention and water holding capacity was studied. Effect of different salt concentration on swelling capacity of synthesized hydrogel was studied. Biodegradability of synthesized hydrogel and impact of biodegraded hydrogel on soil fertility was also investigated.

\section{EXPERIMENTAL}

\section{MATERIAL}

Aloevera powder (Kshipra Biotech Pvt.Ltd.), acrylic acid, Glutaraldehyde, (Loba chemie laboratory reagent and fine chemicals), Ammonium per sulphate (Avantor Performance Material India Ltd.).

\section{Characterization}

Fourier transform infrared (FTIR) spectroscopy 
This characterization method was utilised in order to get an infra-red spectra of the polymer. Fourier transform spectroscopy collects a very high resolution data for wide spectrum range. The molecular entity as well as different structure present gets identified by the bands of IR. FTIR of the polymers under study was procured on Perkin Elmer RXI spectrophotometer using $\mathrm{KBr}$ pellets (Sigma Aldrich).

\section{Scanning electron microscopy (SEM)}

SEM of the polymers was performed on JSM 6100. The surface morphology of candidate polymer and deviations of candidate polymer on graft co-polymerization was studied through Scanning Electron Microscopy (SEM).

\section{X-ray diffraction (XRD) studies}

XRD of samples was done on X' Pert Pro. Small particle size of each samples were thinly pulverized in to powder prior to exposing it to X-ray diffractometry. Coherence length of polymers was computed applying following equation:

$$
\mathrm{L}=0.9 \lambda / \beta 1 / 2 \times \cos \theta
$$

Here, $L=$ coherence length, $\lambda=$ wavelength, $\beta \frac{1}{2}=$ full width half maximum and $\theta^{=}$diffraction angle (Kaith et al., 2010).

\section{Electron dispersive (EDS) studies}

EDS is an analytical technique which is used for the analysis of an element and estimation of its relative abundance. It involves interaction between sample and X-ray source. EDS of the Aloevera and Av-cl-poly(AA) were scrutinized by SU8010, Hitachi.

\section{Preparation of (Av-cl-poly (AA)}

Aloe vera $(1 \mathrm{~g})$ was added in a reaction flask having $10 \mathrm{~mL}$ of water. Then APS was added to it followed by addition of glutaraldehyde with continuous stirring. This was followed by the addition of acrylic acid to the reaction mixture and was stirred meticulously until homogenous mixture was obtained. Synthesized hydrogel was then dried till constant weight was attained.

Different reaction parameters like concentration of initiator, monomer, cross-linker, reaction time, amount of solvent, temperature and $\mathrm{pH}$ were optimized with respect to percentage 
swelling $\left(\mathrm{P}_{\mathrm{s}}\right)$ as per equation given below:

$$
P_{s}=\frac{W_{s}-W_{d}}{W_{d}} X 100
$$

where $\mathrm{W}_{\mathrm{s}}$ and $\mathrm{W}_{\mathrm{d}}$ are weights of swelled and dry Av-cl-poly(AA), respectively (Chaudhary et al., 2018; Kaith et al., 2010; Mittal et al., 2010 and Saruchi et al., 2014).

\section{Swelling studies in various chloride salt solutions}

Impact of ionic strength of variable positively charged ions of diverse ionic strength like 0.01 , $0.02,0.03,0.04$ and $0.05 \mathrm{~mol} \mathrm{~L}^{-1}$ on $\mathrm{P}_{\mathrm{s}}$ of formulated polymers was premeditated in $\mathrm{NaCl}$, $\mathrm{KCl}, \mathrm{CoCl}_{2} .6 \mathrm{H}_{2} \mathrm{O}, \mathrm{BaCl}_{2}$ and $\mathrm{FeCl}_{3}$ salt solution, at a pre-optimized time, temperature as well as $\mathrm{pH}$.

\section{Measurement of water-retention capacity of soil by Av-cl-poly(AA)}

Water retention capacity of soil using Av-cl-poly(AA) was studied in two types of soils: clay soil and sandy loam soil. Five samples $0.5 \mathrm{~g}, 1.0 \mathrm{~g}, 1.5 \mathrm{~g}, 2.0 \mathrm{~g}$ and $2.5 \mathrm{~g}$ of each synthesized hydrogel Av-clpoly(AA) were mixed thoroughly with $50 \mathrm{~g}$ of dry soil in disposable container separately. Then $100 \mathrm{~mL}$ of water was added and the initial weight of the sample was taken. Container having soil and water, without hydrogel was referred as control, while the containers with hydrogels were taken as test samples. Regularly upto 25 days weights of the samples were taken and water retention capabilities of the soil with and without hydrogel were studied (Danahue et al., 1971). Residual water (g/g) was calculated from the equation given below:

$$
\text { Residual water }=\left(\mathrm{W}_{\mathrm{f}}-\mathrm{W}_{\mathrm{i}} / \mathrm{W}_{\mathrm{i}}\right)
$$

Where, $\mathrm{W}_{\mathrm{f}}$ and $\mathrm{W}_{\mathrm{i}}$ are the final and initial weights of the samples, respectively

\section{Measurement of water uptake by clay and sandy loam soils using swollen hydrogel}

Two different soil samples clay and sandy loam were taken for this experiment. Soil samples were collected from the upper layer $(0-50 \mathrm{~cm})$. Then soils were air dried. Known amount of dried Av-cl-poly(AA) were kept in tea bags and immersed in $100 \mathrm{~mL}$ of water, so as to soak water for $24 \mathrm{~h}$. After $24 \mathrm{~h}$ tea bags were taken out from the water and gently wipe with tissue paper, so that excess of water can be removed. Then these tea bags were kept in dry clay and sandy loam soils. After interval of $4 \mathrm{~h}$ these tea bags were weighed until the equilibrium was attained (Miller, 1979; Nandi and Brave, 201; Raafat et al., 2012). 


\section{Characterization}

\section{Fourier transform infra-red (FTIR) spectroscopic studies}

FT-IR of the synthesized polymers was performed on Perkin Elmer spectrophotometer

\section{Aloe vera}

IR spectrum of Aloevera showed wider peak at $3325 \mathrm{~cm}^{-1}$ because of $\mathrm{O}-\mathrm{H}$ stretching of $\mathrm{OH}$ group, $2915 \mathrm{~cm}^{-1}$ because of $\mathrm{C}-\mathrm{H}$ stretching of $\mathrm{C}-\mathrm{H}$ group, $2101 \mathrm{~cm}^{-1}$ due to $\mathrm{C} \equiv \mathrm{C}$ elongation of mono-substituted group, $1607 \mathrm{~cm}^{-1}$ because of carbonyl group of $\mathrm{COOH}, 1345 \mathrm{~cm}^{-1}$ because of C-O stretching of tertiary alcohol, $1237 \mathrm{~cm}^{-1}$ because of C-C deformation in the methyl group (Figure 1a).

\section{Av-cl-poly(AA)}

On the other hand, IR spectrum of Av-cl-poly(AA) showed supplementary tips at $2931 \mathrm{~cm}^{-1}$ of C-H stretching, $2659 \mathrm{~cm}^{-1} \mathrm{O}-\mathrm{H}$ of carboxylic acid, $1699 \mathrm{~cm}^{-1}$ of $\mathrm{C}=\mathrm{O}$ stretching of aryl carboxylic acid, $1416 \mathrm{~cm}^{-1} \mathrm{C}-\mathrm{H}$ stretching because of $\mathrm{C}-\mathrm{H}$ group, $1160 \mathrm{~cm}^{-1}$ because of C-C stretching of C-C group (Figure 1b).

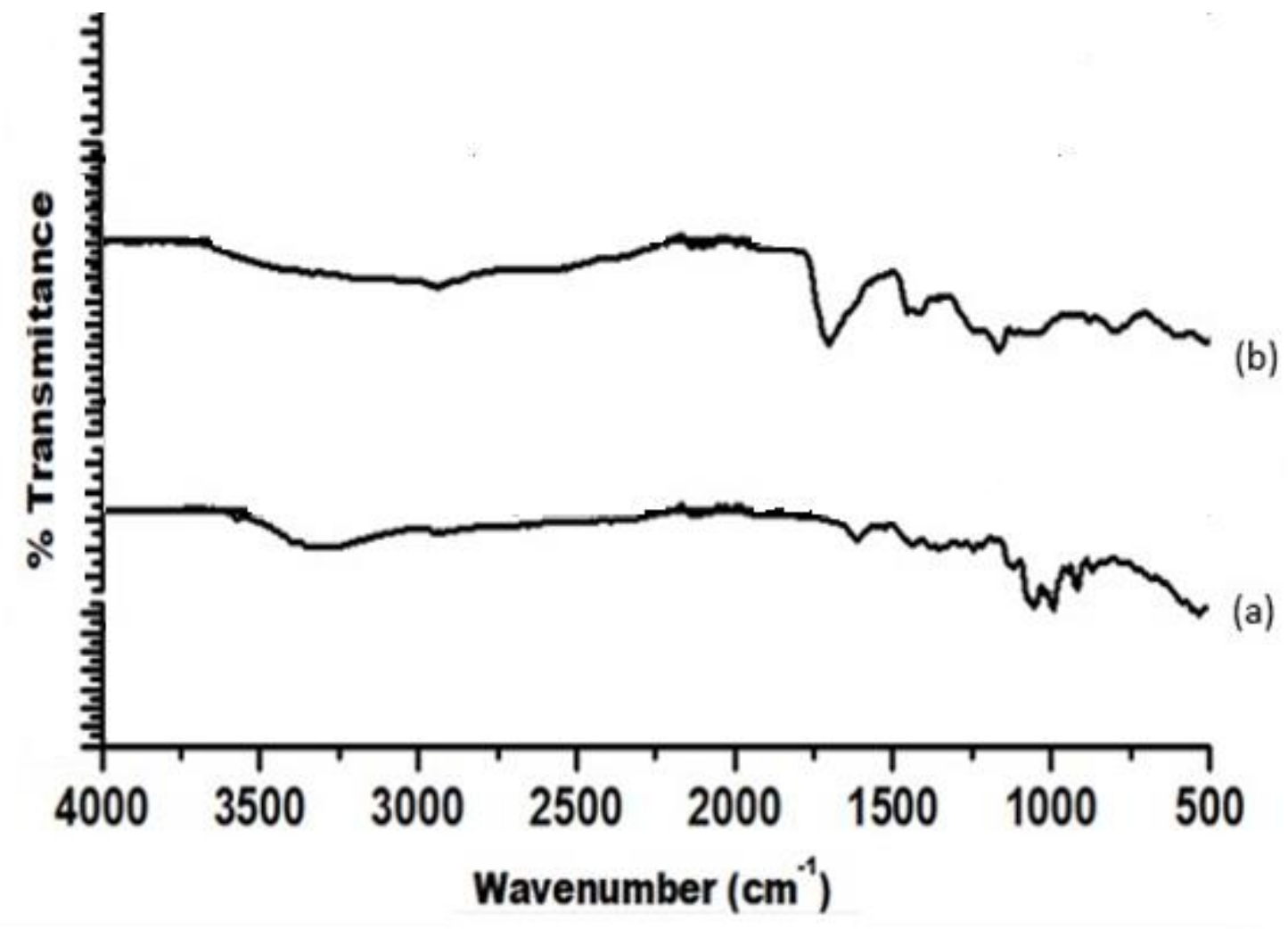


Figures 1a,b: FTIR spectra of (a) Aloevera and (b) Av-cl-poly(AA)

\section{Scanning electron microscopic (SEM)}

The surface morphology of the synthesized candidate polymer on grafting was studied through SEM. Scanning was synchronised with the microscopic rays upholding a small size over a large distance. SEM was performed on JSM-6100. The surface morphology of the Aloevera and Av-cl-poly(AA) were studied by the SEM technique. SEM images of both the samples exhibited morphological differences.

\section{Aloe vera}

Smooth surface was observed in SEM of backbone, Aloevera (Figure. 2a). The surface morphology of backbone did not exhibited any kind of ridges, grooves or pits as observed in figure.

\section{Av-cl-poly(AA)}

Rough surface bearing depressions and pits were observed extending throughout the surface of Av-cl-poly(AA), which is not seen in backbone (Figure 2b). The occurrence of such coarse and porous structures in Av-cl-poly (AA) proves the morphological difference by chemical modification of the backbone through grafting as well as cross-linking brought about by covalent bonding in-between polymeric chain on cross-linking through MBA.
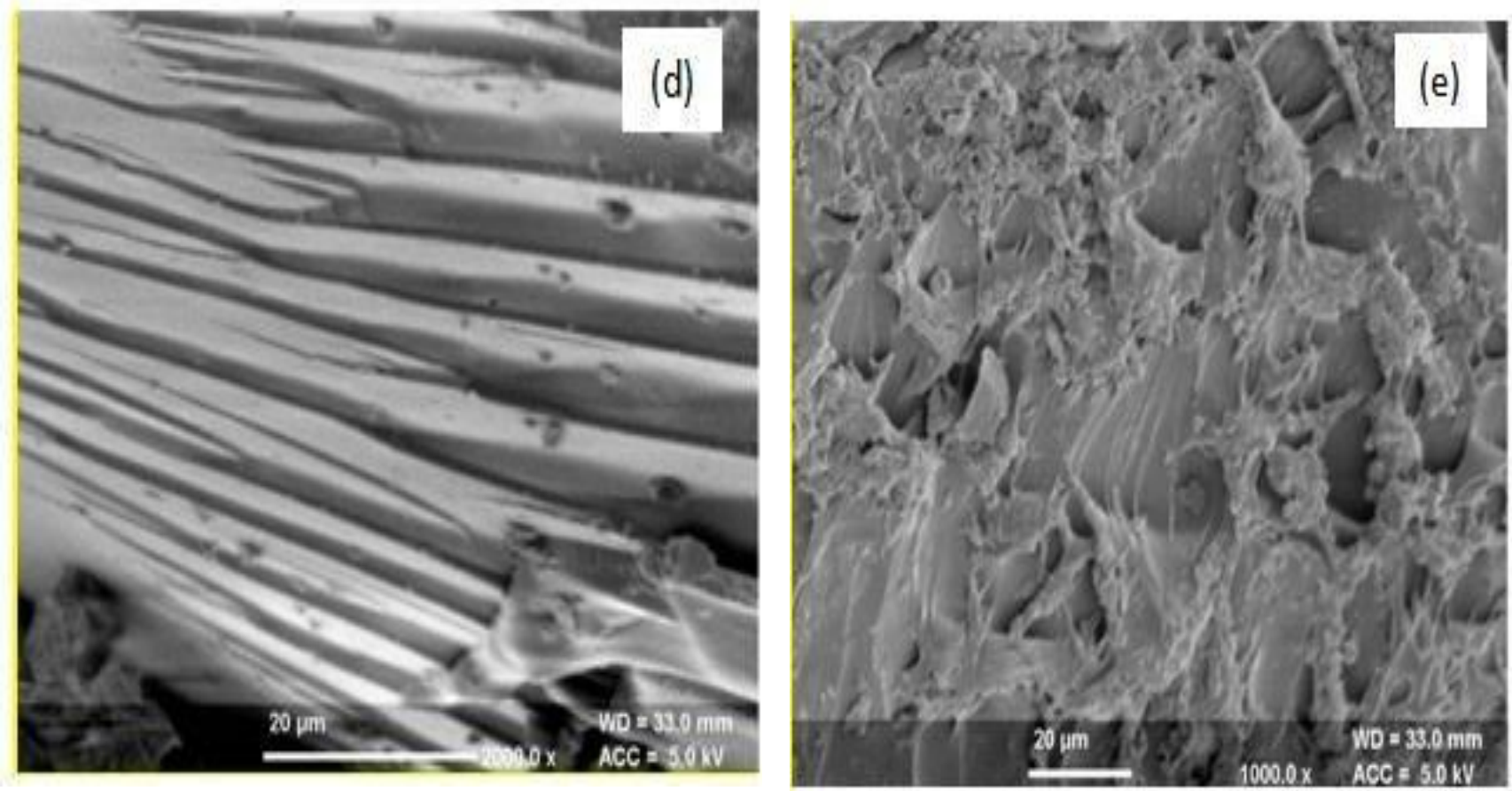
Figures 2a,b: SEMs of (a) Aloe vera and (b) Av-cl-poly(AA)

\section{X-ray diffraction $(\mathrm{XRD})$}

XRD of Aloevera and Av-cl-poly(AA) has been explored by X' Pert Pro, showed the disparity in the anisotropy of Aloevera and Av-cl-poly(AA)

\section{Aloevera}

The coherence length of the samples was calculated by Scherrer equation (Mittal and Kaith, 2010). The coherence length of Aloevera was found to be 0.542 .

$$
\mathrm{L}=0.9 \lambda / \beta^{1 / 2} \mathrm{x} \cos \Theta
$$

where $L=$ coherence length, $\lambda=$ wavelength, $\Theta=$ diffraction angle and $\beta^{1 / 2}=$ full width half maximum. XRD of backbone is shown in Figure 3a.

\section{Av-cl-poly(AA)}

In Av-cl-poly(AA), the rationality (coherence) length is found to be 0.8092 which was higher than the backbone, which showed that the backbone become more crystalline by grafting and cross-linking it with acrylic acid. This is because of the influence of increased cross-linker concentration, thereby enhancing the cross-linking density in-between polymeric chains and hence resulting in greater aligned crystalline lattices. Anisotropy increased with increase in coherence length. It proves that acrylic acid has been grafted on backbone demonstrating successful grafting. XRD of Av-cl-poly (AA) is shown in Figure $3 b$. 


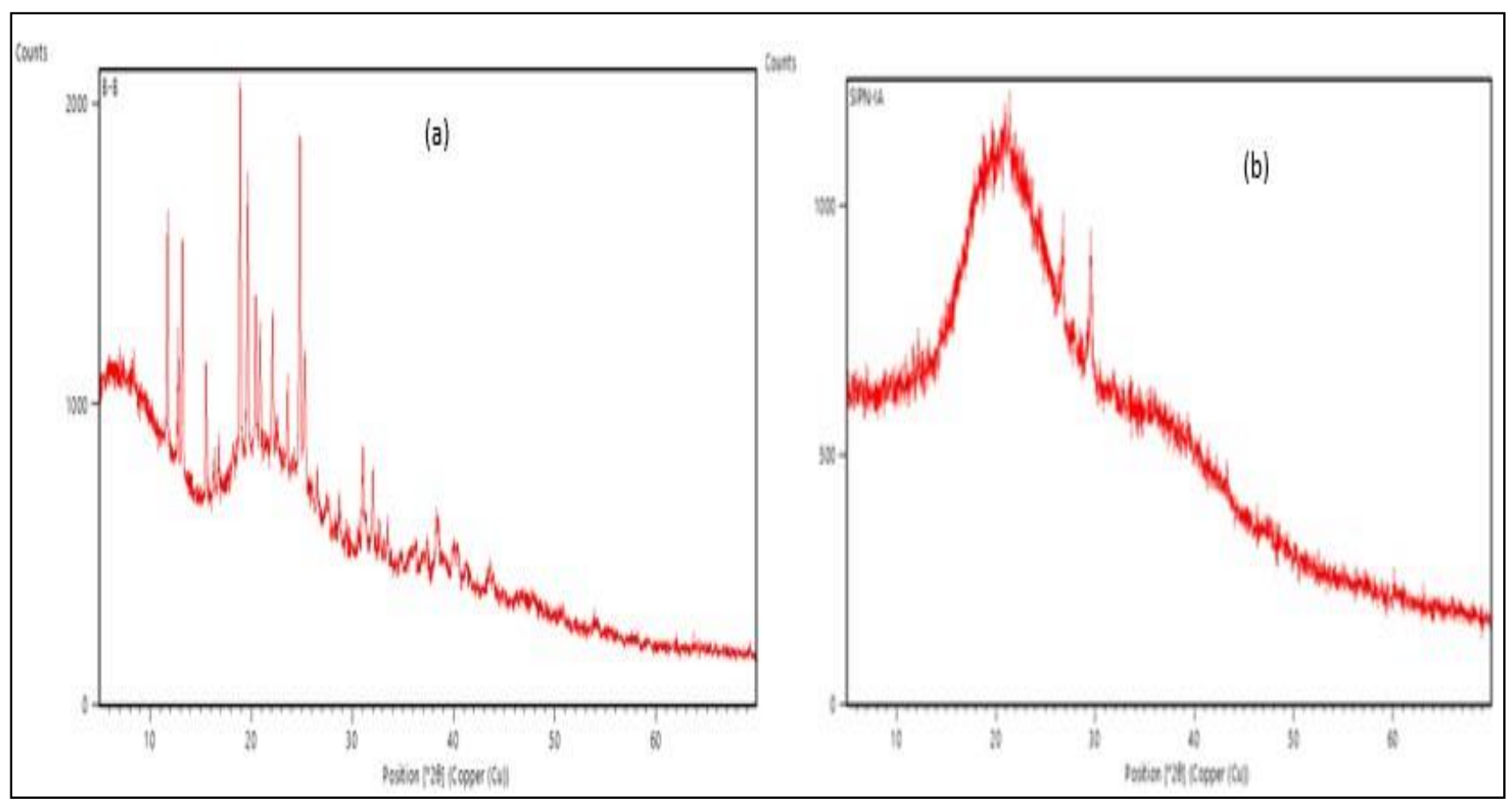

Figures 3a,b: XRDs of (a) Aloevera and (b) Av-cl-poly(AA)

\section{Electron dispersive X-ray spectroscopy (EDS):}

EDS is used for analytical examination of the present elements as well as for the estimation of its relative abundance. It includes an interactive communicative interaction in-between Xray source as well as sample. A high-energy beam of electrons is focused onto the sample under study. The incident beam causes the excitation of electrons, ejecting them and creating a hole. The electron from higher energy level, shifts to the hole, consequently difference in energy of higher and lower energy shells gets escaped in the form of X-ray. The quantity and energy released is noted by the ED spectrometer. Line intensities of various elements present in the samples are measured.

\section{Aloe vera}

Carbon, oxygen and nitrogen were found to be the main elements present in aloe vera backbone. It was found that the atomic \% of carbon in backbone was $53.02 \%$. The atomic percentages of oxygen in backbone, was determined to be $42.77 \%$ and nitrogen in backbone was $4.22 \%$, correspondingly (Figure $4 a$ ). 


\section{Av-cl-poly(AA)}

Carbon, oxygen and nitrogen were found to be the main elements present in Av-cl-poly(AA). It was found that the atomic \% of carbon were $55.22 \%$. The atomic percentage of oxygen was $42.35 \%$ and nitrogen was $2.43 \%$ (Figure $4 \mathrm{~b}$ ). The decrease in atomic \% of oxygen is because of the exclusion of $\mathrm{H}_{2} \mathrm{O}$ molecule.
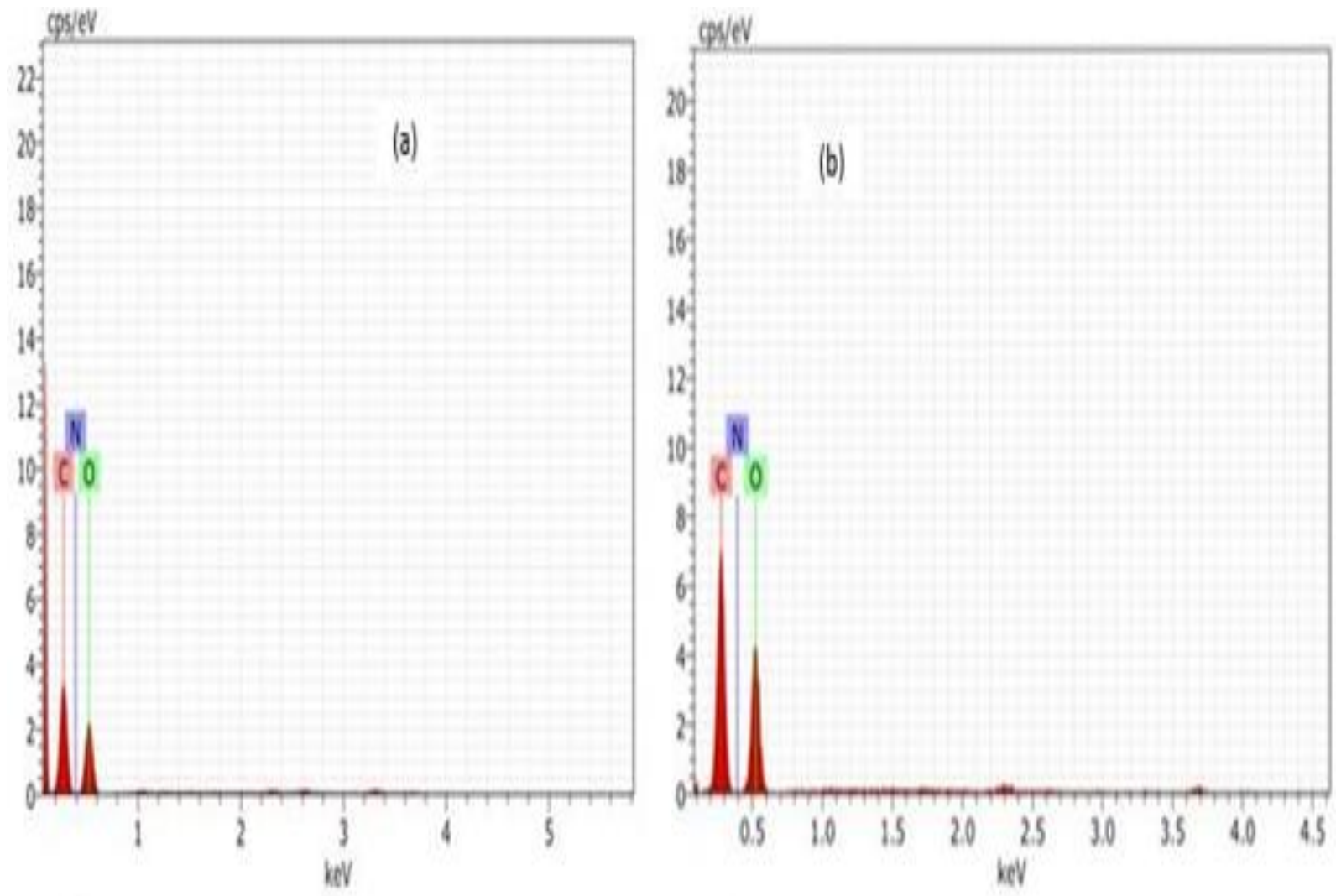

Figures 4a,b: EDS of (a) Aloe vera and (b) Av-cl-poly(AA)

Biodegradation studies of Av-cl-poly(AA) by soil burial, composting and vermicomposting method

Biodegradation behavior of synthesized Av-cl-poly(AA) was studied by soil burial, composting and vermicomposting method. The soil utilized for biodegradation studies were taken from garden of CT Institute, Jalandhar in case of soil burial method. The compost for the biodegradation study was taken from the waste water release from CT campus, Jalandhar and vermicompost was purchased from nursery, respectively. The water level was maintained to avoid drying of the soil by evaporation. The compost rich in microbial species was regularly fed to the samples contained in the pot to enrich and nourish the medium with lot of 
microbes. Synthesized hydrogel was placed at a distance of $3 \mathrm{~cm}$ apart from each other, while placing them in the respective soil sample. Samples were weighed after regular interval of 7 days. Biodegradation of the samples were validated by FT-IR and SEM characterization.

\section{Results and discussion}

\section{Optimization of reaction parameters of Av-cl-poly(AA)}

\section{Impact of reaction time}

It is clear from the (Figure 5a) that $\mathrm{P}_{\mathrm{s}}$ rises with upsurge in reaction time and achieving $596 \%$ of swelling at time interval of $90 \mathrm{~min}$. However, further increase in reaction time resulted in decrease in $\mathrm{P}_{\mathrm{s}}$. Percentage swelling primarily increases with time, it may be pertaining to enhanced the interactions between $* \mathrm{OH}$ and substrate that leads to cohortion of active sites on backbone as well as monomer chains, ensuing in improved $\mathrm{P}_{\mathrm{s}}$. Further increment in reaction time will cut down the $\mathrm{P}_{\mathrm{s}}$. It may be due to preponderance of homo- polymerization over graft copolymerization. Homo-polymerization boost the viscosity of reaction medium, by this means putting impediments in path of free radicals approaching active sites. Therefore $\mathrm{P}_{\mathrm{s}}$ decreases (Nagarjuna et al., 2016).

\section{Impact of reaction temperature}

Maximum Ps $\left(426 \%\right.$ ) was obtained at $60^{\circ} \mathrm{C}$, but further rise in temperature decrease in $\mathrm{P}_{\mathrm{s}}$ (Figure $5 \mathrm{~b}$ ). This may be due to the reason that, upsurge in the temperature above the optimal point, kinetic energy of free radicals rises, inferring in enhanced conflicts as well as termination reactions. Abstraction of hydrogen ion and homo-polymerization at high temperature leads to decrease in $\mathrm{P}_{\mathrm{s}}$. Furthermore, with rise in temperature, the elasticity of polymer matrix upshots and some additional hydrogen bonds are formed. But beyond optimum temperature the hydrogen bonds break down, thereby lowering the $\mathrm{P}_{\mathrm{s}}$ (Mittal et al., 2010 and Mittal et al., 2018).

\section{Impact of pH}

Maximum $\mathrm{P}_{\mathrm{s}}(312 \%)$ under the Impact of microwave radiations was scrutinised under neutral medium (Figure 5c). $\mathrm{P}_{\mathrm{s}}$ was observed to diminish in acidic and basic medium that 
might be because of premature cessation of polymerization reaction. It might also be owing to repression in the formation of per sulphate ion.

\section{Impact of initiator ratio}

It is noted that percent swelling increases with increase in the amount of APS and reached to optimum value $796 \%$ (Figure 5d). Initially $\mathrm{SO}_{4}{ }^{-*}$ and $* \mathrm{OH}$ ion concentration increased resulting in generation of more active sites, thereby increasing Ps. But increase in APS concentration beyond the optimum level decrease the $\mathrm{P}_{\mathrm{s}}$ due to release of large amount of hydroxyl and sulphate ions in the reaction mixture, which leads to the termination of the reaction (Singhal et al., 2009).

\section{Impact of amount of solvent}

Increase in the amount of solvent, resulted in increased $\mathrm{P}_{\mathrm{s}}$ and at certain optimum point the $\mathrm{P}_{\mathrm{s}}$ starts decreasing. Maximum Ps of $736 \%$ was obtained using $14 \mathrm{~mL}$ of solvent during grafting (Figure 5e). It could be explained on the ground that initially there was ample amount of *OH concentration, which propagated the polymerization reaction up to some optimal level. However, any further increase in solvent leads to the end of polymerization reaction because of generation of excessive $* \mathrm{OH}$ concentration (Suruchi et al., 2014).

\section{Impact of cross-linker concentration}

The optimum amount of glutaraldehyde for the reactions was $0.0139 \mathrm{molL}^{-1}$ (459\%) (Figure $5 \mathrm{~g}$ ). Increase in cross-linker concentration above optimum concentration leads to decrease in $\mathrm{P}_{\mathrm{s}}$. Initially, $\mathrm{P}_{\mathrm{s}}$ increases because surface area of the grafted cross-linked moiety increases. But with further increase in the concentration of cross-linker, leads to compacting of polymeric chains. Thereby, decreasing pore size, which further leads to desorption and thus, reduced the percentage swelling (Tokuyama et al., 2007).

\section{Impact of monomer concentration}

Maximum Ps, $318 \%$ was observed at acrylic acid concentration of $4.1632 \mathrm{~mol} \mathrm{~L}^{-1}$. Increasing acrylic acid concentration above optimum concentration decreases $P_{s}$ (Figure 5f). It may be due to the fact that further increase in the amount of monomer predominate the homopolymerisation over grafting. Moreover the cross-linking density increases and Av-clpoly(AA) becomes more compact. Moreover, the accessibility of water molecules towards functional group present in the polymeric chain also decreases, thereby decreasing the $\mathrm{P}_{\mathrm{s}}$ (Anupama et al., 2002). 

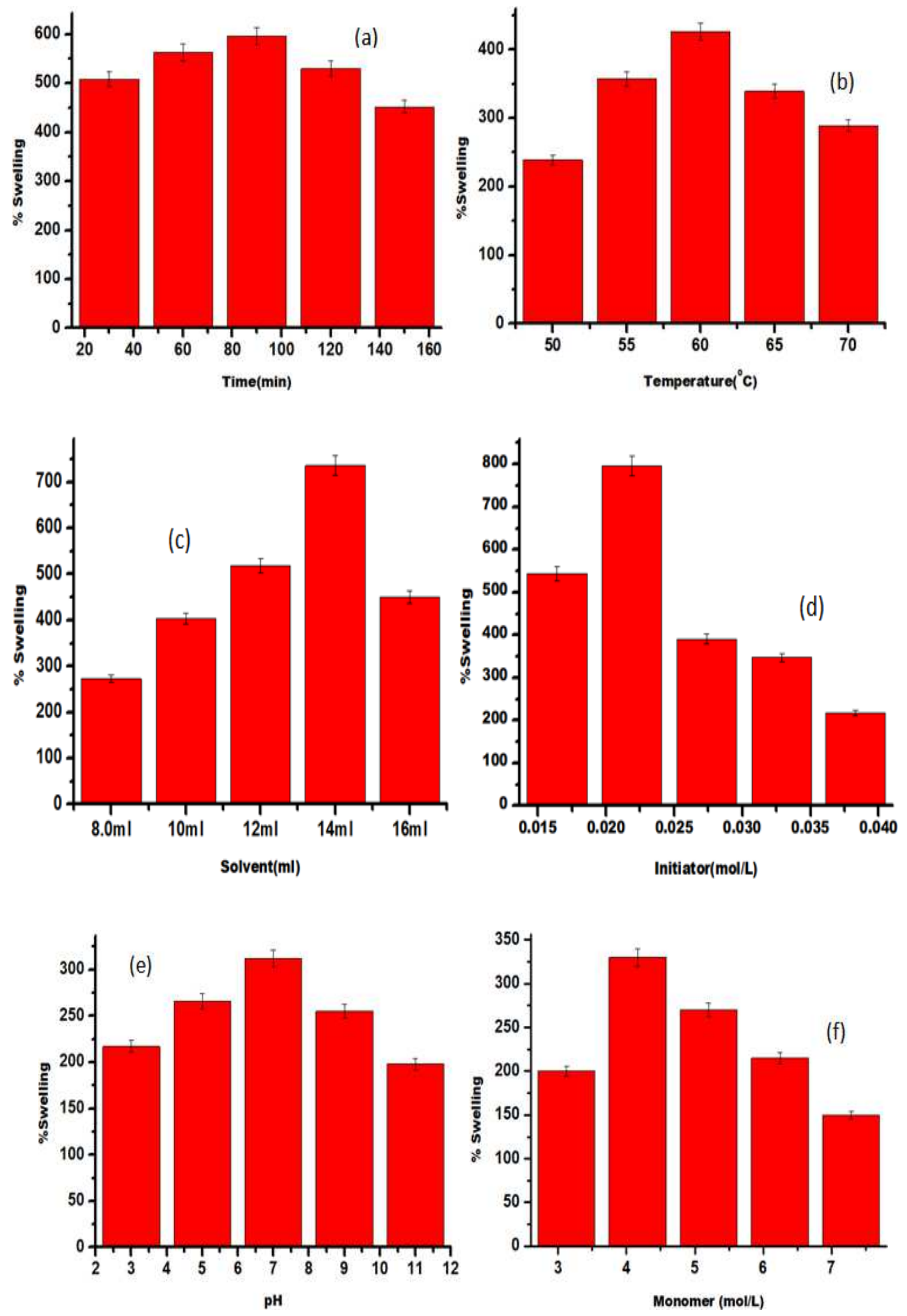


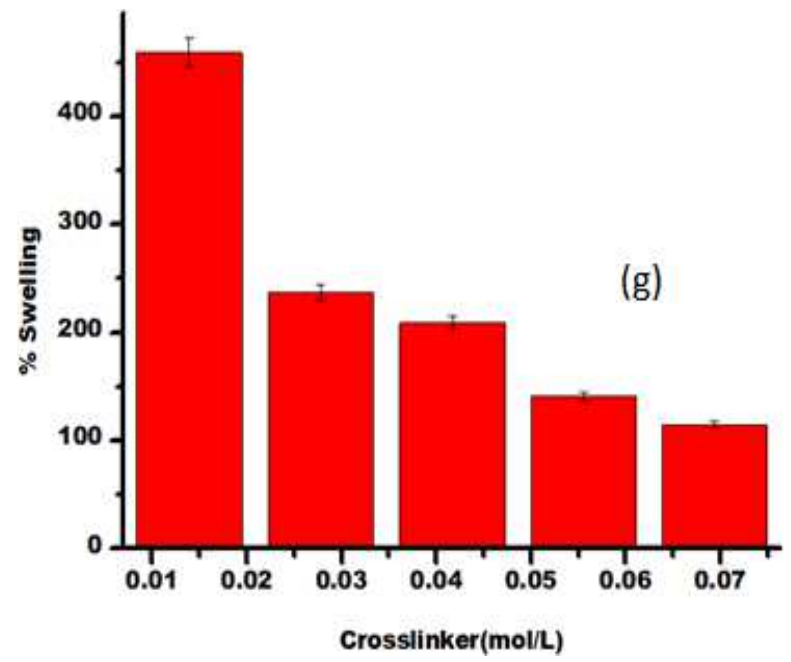

Figures 5a-g: Impact of (a) time; (b) temperature; (c) solvent; (d) initiator concentration; (e) pH; (f) monomer concentration and (g) cross linker concentration on Ps of Av-cl-poly (AA)

Swelling studies of Av-cl-poly (AA) in de-ionised water

Swelling behavior of Av-cl-poly(AA) was studied as a function of time, temperature and $\mathrm{pH}$ of the swelling medium.

Impact of time on percent swelling 
Av-cl-poly(AA) showed utmost swelling of $242 \%$ at 2160 minutes and thereafter Ps decreases with further increase in time (Figure 6a). Because the porous network was already saturated and do not accommodate any more solvent molecules with further increase in time (Alonso et al., 2007).

\section{Impact of temperature on percent swelling}

Impact of temperature on swelling behavior of Av-cl-poly(AA) was studied at different temperatures $\left(40,50,60\right.$ and $70,80^{\circ} \mathrm{C}$ ) at preoptimized time (Figure $6 \mathrm{~b}$ ). It was found that Ps increased with the increase in temperature and maximum Ps was achieved at $70^{\circ} \mathrm{C}(\mathrm{Ps}=$ $552 \%)$. Further increase in temperature, beyond optimized temperature leads to decrease in Ps. This may be due to the fact that with increase in the temperature, the flexibility of Av-clpoly(AA) matrix also increases. As a result of which the disruption of secondary interactions takes place, thereby generating more spaces for diffusion of water molecules. Above optimum temperature, the matrix obtained started to collapse, which lead to desorption and consequently decreasing swelling (Hussein et al., 2017).

\section{Impact of pH on Ps of Av-cl-poly (AA)}

Maximum Ps (556\%) of Av-cl-poly(AA) was recorded in the neutral medium (Figure 6c). This can be explained on the basis that in the neutral medium, there are sufficient number of hydrogen ions and it protonates the functional group present in the polymer. As a result of which the polymeric chains are repelled, allowing more water molecules into the matrix, thereby, increases the percentage swelling. In an alkaline medium, the de-protonation of the functional groups takes place, due to which repulsions in-between the polymeric chains decreases. The rigidity of the structure increases, thereby reducing $\mathrm{P}_{\mathrm{s}}$ (Budianto et al., 2015).

\section{Impact of ionic strength and ionic charge on Ps of Av-cl-poly(AA)}

Ionic strength of different cations $\left(\mathrm{Na}^{+}, \mathrm{K}^{+}, \mathrm{Ba}^{2+,} \mathrm{Co}^{2+}, \mathrm{Fe}^{+3}\right)$ on the $\mathrm{P}_{\mathrm{s}}$ of $\mathrm{Av}$-cl-poly(AA) in different chloride salt solutions was examined (Figure 6d). It was noted that with increase in ionic strength of cation, there is a sharp decline in Ps in respective salt solutions. Decrease in Ps with increase in ionic strength of cations might be due to the reverse osmosis process. It was also found that increase in ionic strength of cations, leads to increase in the concentration of mobile ions in solution, which leads to decrease in the osmotic swelling pressure ( $\pi$ ions), thus leads to decrease in Ps. It was found that increase in cationic charge led to decrease in Ps, this may be due to the fact that increase in ionic charge leads to increase in proportionate of 
cationic-cationic repulsion, which do not permit further access of solution containing cations in the cross-linked network by this means ensuing in desorption of cations. Maximum Ps $248 \%, 268 \%, 250 \%, 236 \%$ and $182 \%$ was found in $\mathrm{NaCl}, \mathrm{KCl}, \mathrm{BaCl}_{2}, \mathrm{CoCl} .6 \mathrm{H}_{2} \mathrm{O}$ and $\mathrm{FeCl}_{3}$ salt solutions having 0.01 molL ${ }^{-1}$ ionic strength of $\mathrm{Na}^{+}, \mathrm{K}^{+}, \mathrm{Ba}^{+2}, \mathrm{Co}^{+2}$ and $\mathrm{Fe}^{+3}$, correspondingly (Gupta and Shivakumar, 2012; Kumar et al., 2015).
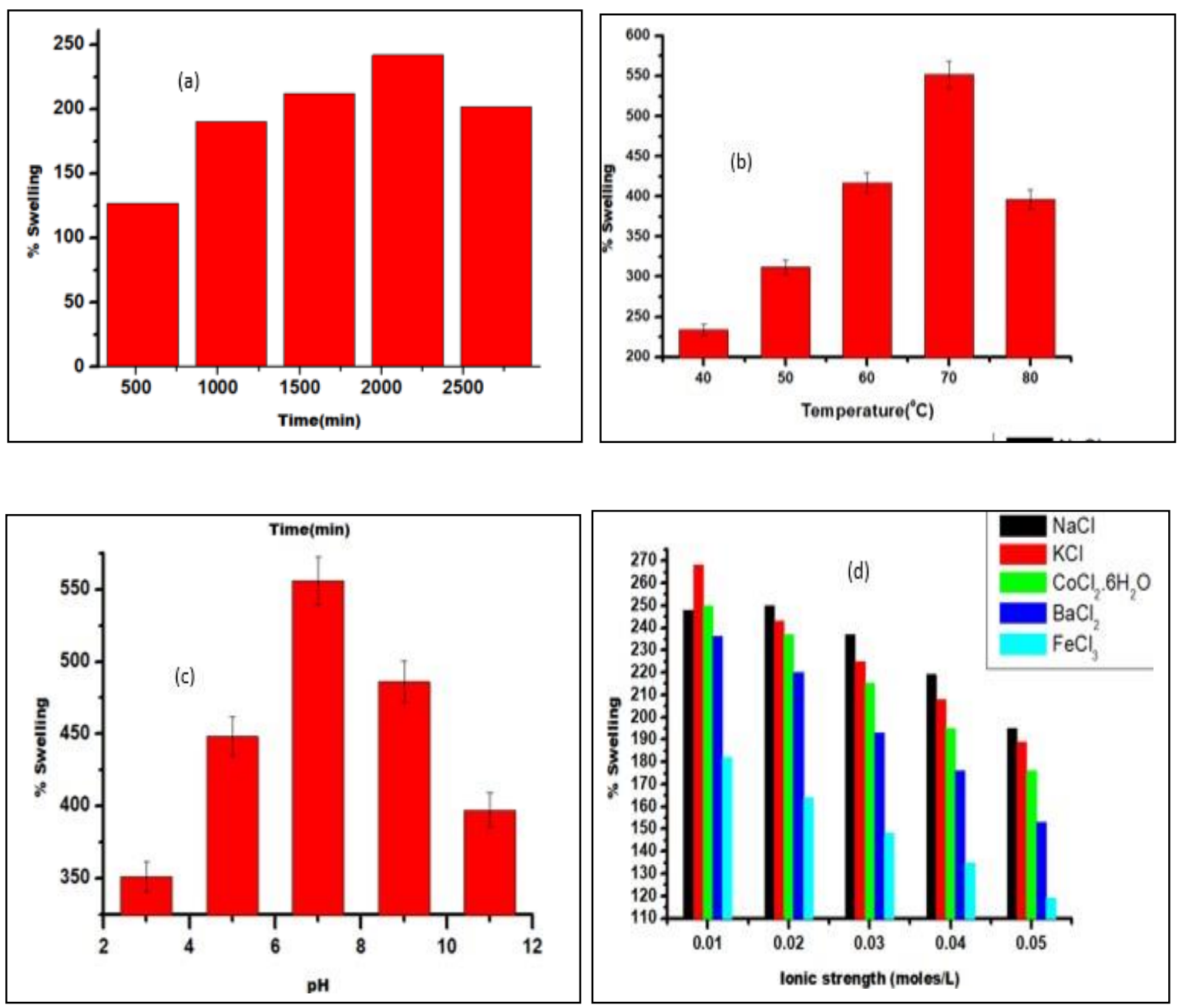

Figures 6a-d: Impact of (a) time; (b) temperature; (c) pH; and (d) ionic strength on Ps of Av-cl-poly (AA)

\section{Biodegradation study of synthesized Av-cl-poly(AA)}

\section{Biodegradation behavior using soil burial method}

Synthesized polymers were subjected to biodegradation and the process was carried for time 
period of 70 days. Maximum weight loss due to biodegradation of Av-cl-poly(AA) was found to be $90 \%$, after 70 days (Table 1). The degradation of Av-cl-poly(AA) occurred because of the disruption of covalent bonds by microorganisms present in the soil, disintegrating bulky molecular species into simpler ones (Premraj and Doble, 2005).

\section{Biodegradation using compositing method}

It was observed that Av-cl-poly(AA) underwent degradation in 70 days in compost soil. Maximum weight loss due to biodegradation through composting method was found to be

after

70

days 
(Table 1). Biodegrading of the Av-cl-poly(AA) occurred by enzymatic and chemical decomposition. The microbe-rich composting material leads to the enzymatic and chemical decomposition, which cleaves the chemical bond of Av-cl-poly(AA) and hence disintegration takes place. Compost provides nitrogen to bacteria and fungi, which are helpful in degrading polymeric structure. Diverse phases of biodegradation were verified through FT-IR and SEM.

\section{Biodegradation using vermi-compositing method}

It was observed that synthesized hydrogel underwent maximum degradation $93 \%$ with vermin-composting method in 70 days (Table 1). The microorganism causes chemical and enzymatic decomposition of the Av-cl-poly(AA) thereby cleaving the chemical bond and leads to disintegration of Av-cl-poly(AA). Biodegradation were further verified via FT-IR and SEM.

Table 1: Biodegradation study of synthesized Av-cl-poly(AA) through soil burial, Composting and vermicomposting method

\begin{tabular}{|l|l|l|l|l|l|l|l|l|l|l|}
\hline \multicolumn{8}{|c|}{ Percentage weight loss at different time intervals (Days) } \\
\hline $\begin{array}{c}\text { Biodegradation method } \\
\text { of Av-cl-poly(AA) }\end{array}$ & 7 & 14 & 21 & 28 & 35 & 42 & 49 & 56 & 63 & 70 \\
\hline Soil Burial Method & 7 & 14 & 22 & 30 & 39 & 47 & 59 & 70 & 81 & 90 \\
\hline Composting method & 9 & 16 & 24 & 32 & 42 & 50 & 61 & 72 & 83 & 94 \\
\hline $\begin{array}{l}\text { Vermicomposting } \\
\text { method }\end{array}$ & 8 & 16 & 23 & 30 & 40 & 49 & 60 & 70 & 81 & 93 \\
\hline
\end{tabular}

\section{Evidences of biodegradation through FT-IR}

A great distinction in peak positions of FT-IR of biodegraded hydrogel is observed because of hydrolysis and enzymatic reactions occurred at the time of biodegradation. At the initial stage biodegradation was slow, but with the passage of time it was increased, this can be explained on the basis in the initial stage surface of the synthesized hydrogel was hard and it 
took time for the microorganism to invade in it, but as the time increased the hydrogel was exposed to moisture and it became soft and easily assessable to the microorganism (Mittal et al., 2018).

\section{FT-IR of various biodegradation stages of Av-cl-poly(AA)}

It was found that the peaks, which were seen in Av-cl-poly(AA) before biodegradation (Figure 1a) on 2128-1864 $\mathrm{cm}^{-1}$ were missing during first stage of biodegradation and some of the peaks 2931-2659 $\mathrm{cm}^{-1}$ and $1699-1051 \mathrm{~cm}^{-1}$ were shifted as seen in (Figures 7a,d,g). In the second biodegradation phase peaks observed at $3427 \mathrm{~cm}^{-1}$ and $1453 \mathrm{~cm}^{-1}$ in first stage were found

missing 
and some of the peaks at $3088-1921 \mathrm{~cm}^{-1}$ were shifted (Figures $7 \mathrm{~b}, \mathrm{e}, \mathrm{h}$ ). This may be due to the degeneration of cross-linking between Aloevera and poly acrylic acid chains. In the third stage of biodegradation, as seen in, peaks observed at 3870-3388 $\mathrm{cm}^{-1}, 3068-2898 \mathrm{~cm}^{-1}$ and peak at 2321 $\mathrm{cm}^{-1}$ were missing and peaks corresponding to $3152 \mathrm{~cm}^{-1}, 2656-2575 \mathrm{~cm}^{-1}, 2114-1404 \mathrm{~cm}^{-1}$ were shifted as seen in (Figures. 7c,f,i), this may be due to the fact that intensity of peak due to $-\mathrm{OH}$ group present over backbone was found to decrease progressively because of biodegradation. The missing and the shifting of the peaks showed that the synthesized hydrogel is biodegradable as well as eco-friendly in its nature. 


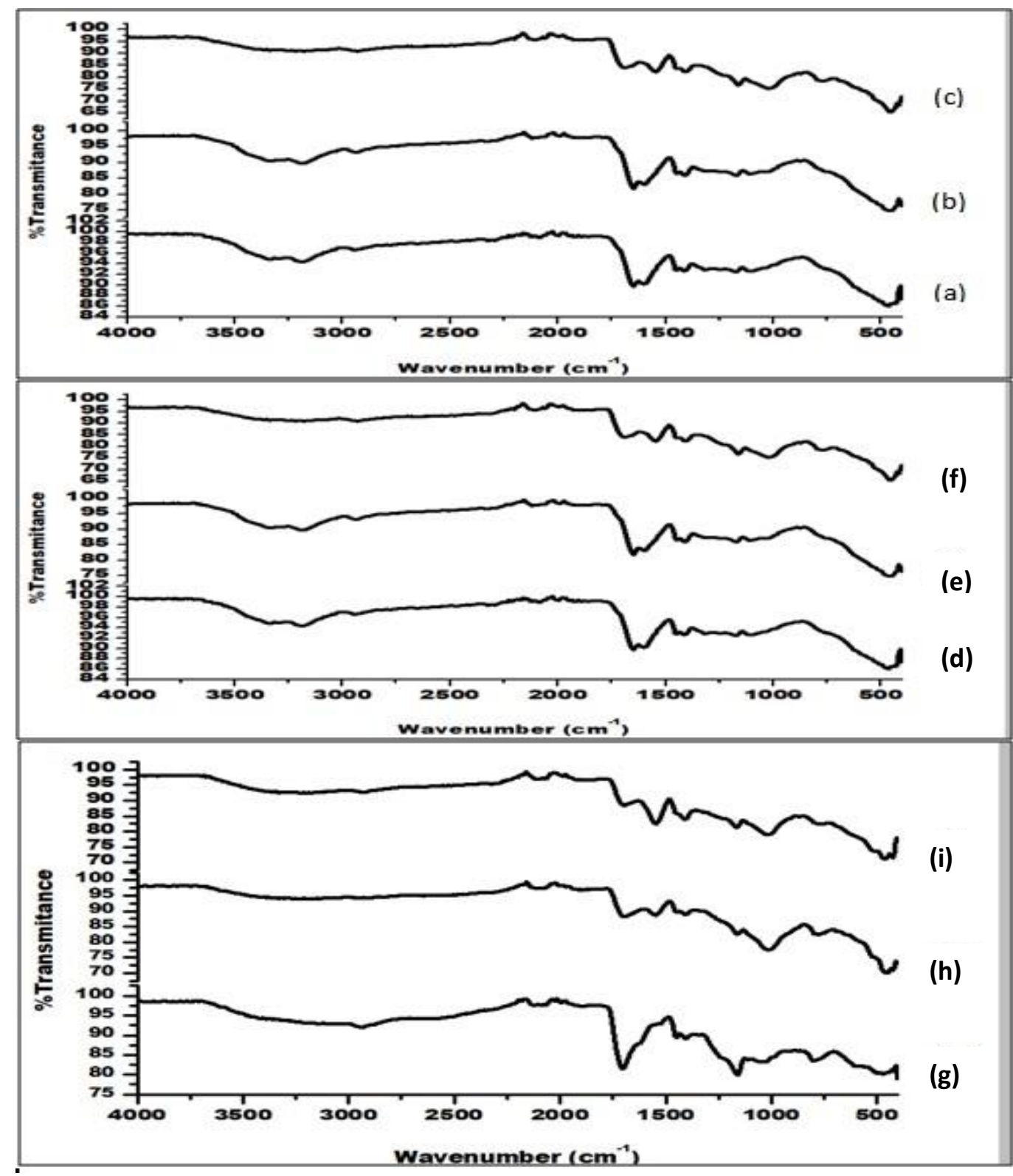


method (d) Av-cl-poly(AA) stage-I; (e) Av-cl-poly(AA) stage-II and (f) Av-clpoly(AA) stage-III using composting method; (g) Av-cl-poly(AA) stage-I; (h) Av-cl-poly(AA) stage-II; (i) Av-cl-poly(AA) stage-III using vermicomposting method

\section{SEM studies of various biodegradation stages of Av-cl-poly(AA)}

SEM results revealed that the biodegradation of hydrogel occurred at different phases as seen in Figures 8a-i. The apparent fissures were seen in the first stage of biodegradation. The concentration of morphological smash up enlarged with the rise in biodegradation moment (Figures $8 \mathrm{a}, \mathrm{d}, \mathrm{g})$. In the second phase of biodegradation big crevices with further superficial pits were observed (Figures $8 \mathrm{~b}, \mathrm{e}, \mathrm{h}$ ). SEM images clearly showed that in the $3^{\text {rd }}$ stage of biodegradation, there is complete disintegration of Av-cl-poly(AA) occurred (Figures 8c,f,i).
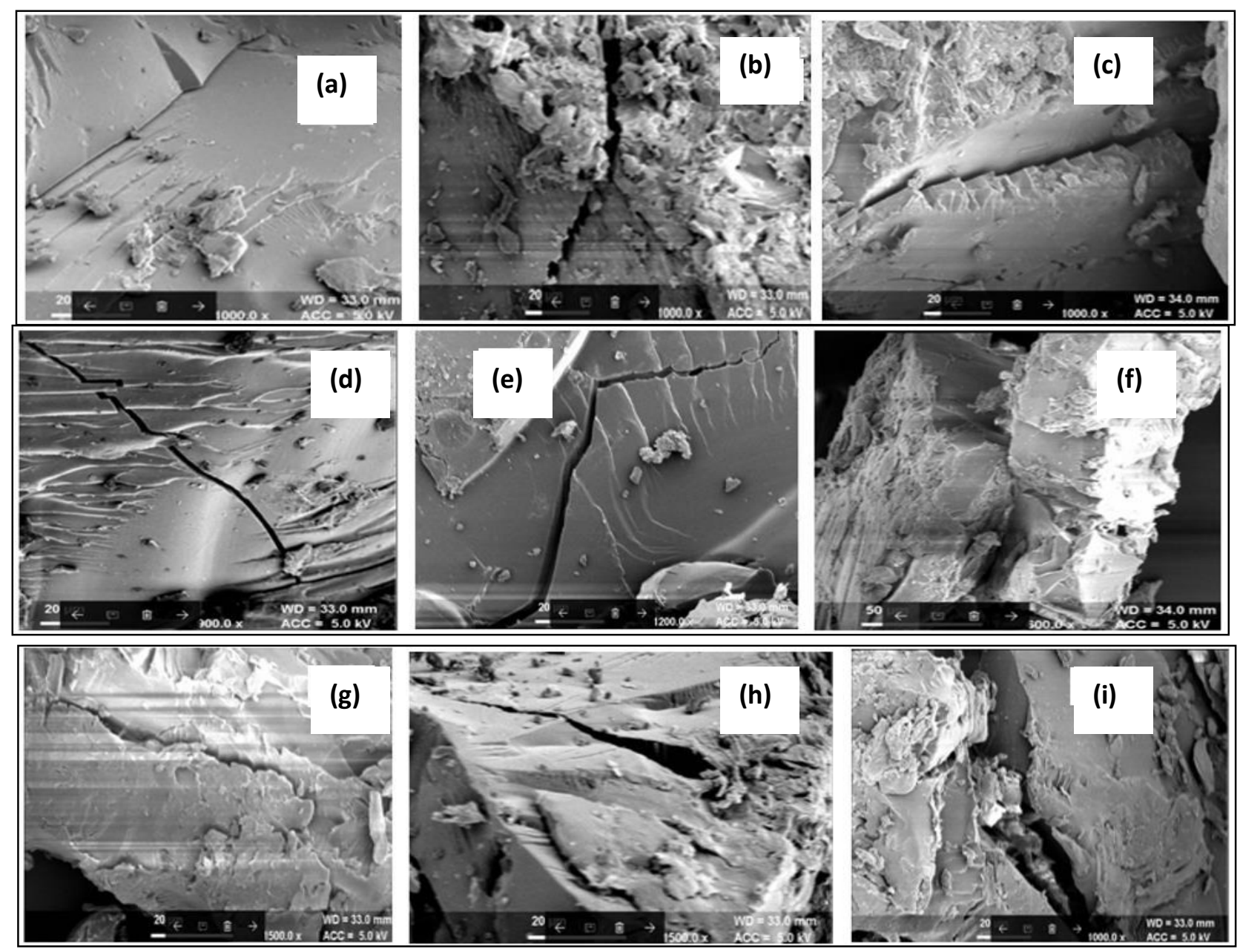

Figures 8a-i: SEMs of biodegradation of (a) Av-cl-poly(AA) stage-I; (b) Av-clpoly(AA) stage-II and (c) Av-cl-poly(AA) stage-III using soil burial method (d) Av-cl-poly(AA) stage-I; (e) Av-cl-poly(AA) stage-II and (f) Av-cl-poly(AA) stage-III using composting method; (g) Av-cl-poly(AA) stage-I; (h) Av-clpoly(AA) stage-II; (i) Av-cl-poly(AA) stage-III using vermi- composting method 


\section{Water retention capacity of soil through Av-cl-poly(AA)}

As the population is increasing and agriculture land is decreasing, there is need of increase agricultural production. This leads to the attention of utilization of hydrogel in agriculture as a novel soil conditioner. Agricultural hydrogel has the capacity to retain water granules for a longer period of time, as they swell many times to their original size, when come in contact with water. These characteristic of the hydrogel make them utilized in agriculture and in desert area. So in the present study hydrogel was used as water retaining device. Soil mixed with Av-clpoly(AA) showed lesser water evaporation as compared to the soil without hydrogel. Residual water left in the control sample was $0.08 \mathrm{~g} / \mathrm{g}$ in clay soil and $0.1 \mathrm{~g} / \mathrm{g}$ in sandy loam soil after11 days. Whereas, in soil mixed with $2.5 \mathrm{~g}$ of Av-cl-poly(AA) water retention capacity prolonged for 20-21 days in clay and sandy loam soil, respectively. The residual water content was found to be $0.56 \mathrm{~g} / \mathrm{g}$ and $0.63 \mathrm{~g} / \mathrm{g}$, (Figures 9a,b), in clay and sandy loam soil respectively. It was clear from the results that water loss from the soil was decreasing with increase in hydrogel amount.

\section{Water uptake by soil samples using swollen Av-cl-poly(AA)}

Water content of the clay and sandy loam soil was increased using swollen Av-cl-poly(AA). It was found that the addition of small amount of swollen Av-cl-poly(AA) (up to 1\%) in dry clay and sandy loam soils, leads to increase in the water content of the respective soil. Water content in the soil was increased until the attainment of equilibrium after $36 \mathrm{~h}$. It is clear from the results that $1.0 \%$ addition of Av-cl-poly(AA) to the clay and sandy loam soil increased the water content to the extent of $6.1 \%$ and $5.79 \%$, respectively (Figures 10a,b). There is no further increase in the water uptake with further increase in time, because the equilibrium was attained between the soil sample and Av-cl-poly(AA). It was clear from the results that the synthesized hydrogel is very effective for the water release purpose in different soil, without having any adverse impact on the soil. This showed that synthesize hydrogel increase the soil texture and porocity of the soil, which ultimately may lead to the enhancement of soil fertility. 

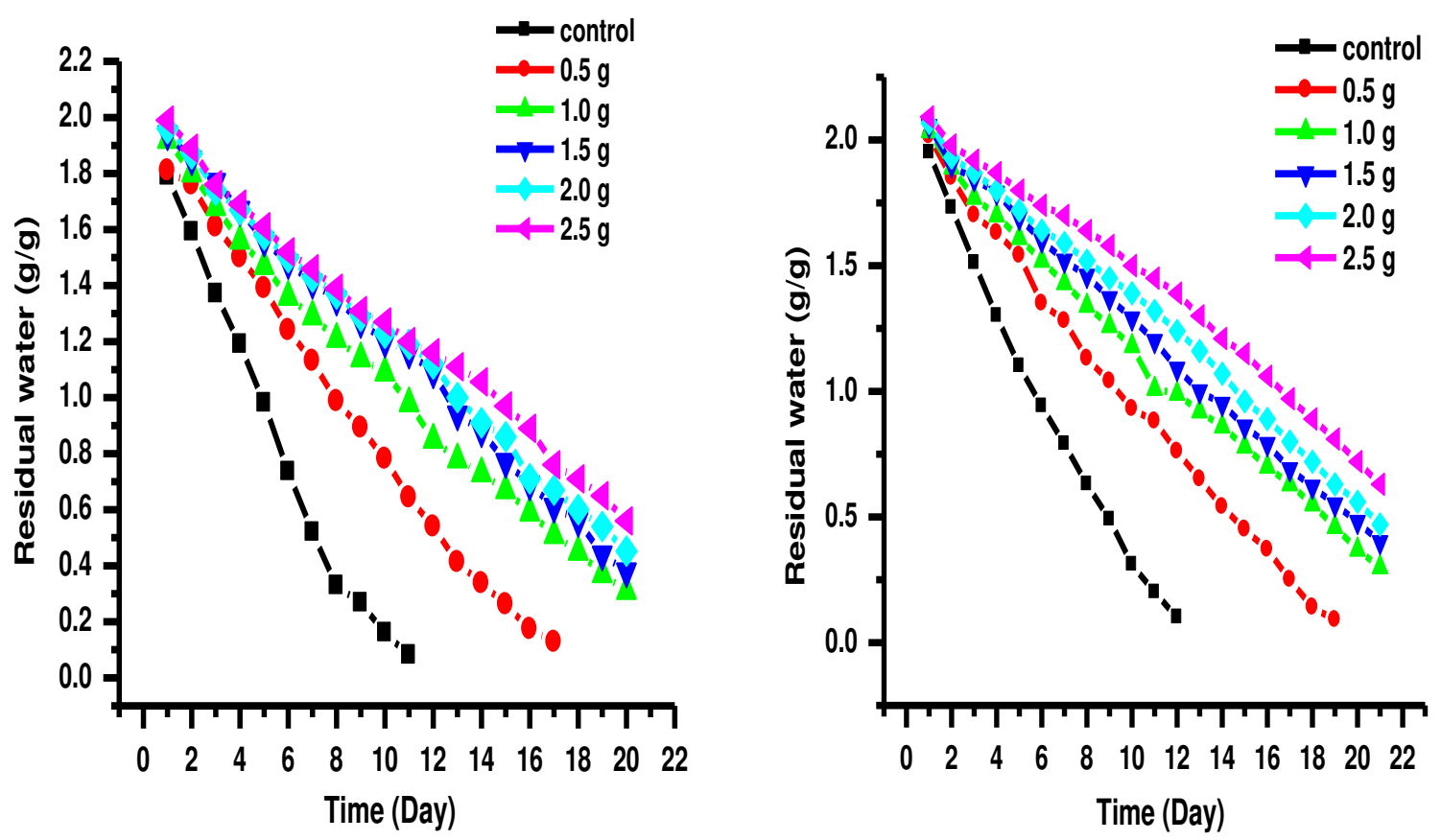

Figures 9a,b: Water retention capacity of (a) clay soil and (b) sandy loam soil using Av-cl$\operatorname{poly}(\mathbf{A A})$ 

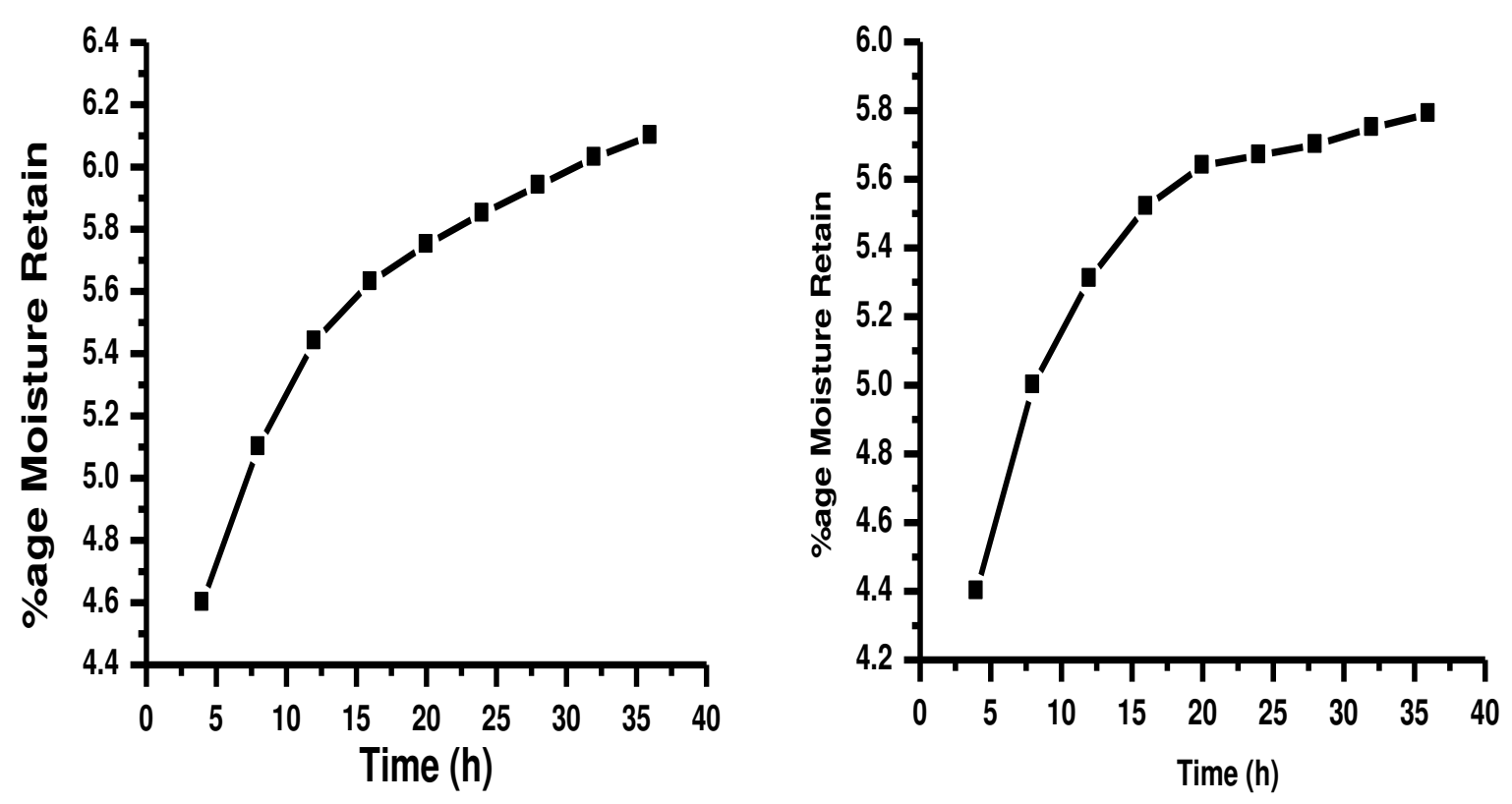

Figures 10a,b: Water retention capacity of (a) clay soil and (b) sandy loam soil using Av-cl$\operatorname{poly}(\mathrm{AA})$

\section{Impact of biodegradation of synthesize hydrogel on soil}

Biodegraded hydrogel impact on soil fertility was studied by carrying-out the soil analysis before and after biodegradation of hydrogel. Organic carbon, phosphorus, potassium contents and $\mathrm{pH}$ of the soil sample was analyzed.

The results revealed that $\mathrm{pH}$ of the control soil was $\mathrm{pH} 6.9$ and organic carbon was $0.31 \%$. Phosphorus and potassium content was $12.5 \mathrm{~g} / \mathrm{m}^{2}$ and $59 \mathrm{~g} / \mathrm{m}^{2}$, respectively (Table 2).

As it is well known that carbon is the one of the constituent for the photosynthesis process and its low value act as a limiting factor for the plant growth (Rajan et al., 2010 and Srinivasarao, et al., 2012). Soil analysis result showed that there is increase in the content $(0.36 \%)$ of $\%$ organic carbon in the soil having degraded hydrogel as compared to the control soil (Table 2).

Phosphorus and potassium are main nutrient, which are required for new plantations and growth of the plants (Brady and Weil, 2002). Potassium and phosphorus in the control soil sample was 
$12.5 \mathrm{~g} / \mathrm{m}^{2}$ and $59 \mathrm{~g} / \mathrm{m}^{2}$, respectively, but in the Av-cl-poly(AA) degraded soil these component are $13.1 \mathrm{~g} / \mathrm{m}^{2}$ and $59 \mathrm{~g} / \mathrm{m}^{2}$ respectively (Table 2 ).

It was clear from the results that there was only small change in the $\mathrm{pH}$ of the control and test soil sample. The $\mathrm{pH}$ was 6.9 in the control sample and it was 6.7 in the soil with degraded hydrogel, which is in the permissible limit of the soil $\mathrm{pH}$ (Table 2).

\section{Conclusion}

It was clear from the foregone discussion that a novel Aloevera-acrylic acid based hydrogel was synthesized. The maximum swelling capacity of the synthesized hydrogel was found to be $796 \%$. Synthesized hydrogel was eco-friendly in nature. It was biodegradable and has no harse impact

\begin{tabular}{|l|l|l|l|l|l|}
\hline S. No. & Samples & $\mathbf{p H}$ & Organic carbon $(\%)$ & Phosphorus $\left(\mathbf{g} / \mathbf{m}^{2}\right)$ & $\begin{array}{l}\text { Potassium } \\
\left(\mathbf{g} / \mathbf{m}^{2}\right)\end{array}$ \\
\hline 1 & Control & 6.9 & 0.31 & 12.5 & 59 \\
\hline 2 & Av-cl-poly(AA) & 6.7 & 0.36 & 13.1 & 59 \\
\hline
\end{tabular}

on the fertility of the soil, rather it enhanced the soil fertility. Maximum biodegradation was found to be $90 \%, 94 \%$ and $93 \%$ in case of soil burial, composting and vermin-composting methods, respectively. It enhanced the water retention and water holding capacity of clay and sandy loam soil. The water retention periods of soil using synthesized hydrogel prolonged from 11 to 20 days. Thus, it can be concluded that synthesized hydrogel is very efficient from agriculture as well as environmental view point.

\section{Acknowledgement}

Authors Dr Saruchi and Dr Vaneet are thankful to CT Group of Institutions for carrying out this research work. 


\section{Conflict of interest}

There is no conflict of interest regarding this manuscript.

\section{Data Availability}

The whole data of the present manuscript is available, it will be provided if asked.

\section{References}

1) Mittal H., Kumar V., Saruchi, Ray S.S., 2016. Adsorption of methyl violet from aqueous solution using gum xanthan/Fe3O4 based nanocomposite hydrogel. International Journal of Biological Macromolecules. 89: 1-11.

2) Saruchi, Kumar V., Mittal H., Alhassan S.M., 2019. Biodegradable hydrogels of tragacanth gum polysaccharide to improve water retention capacity of soil and environment-friendly controlled release of agrochemicals. International J Biol Macromol. 132: $1252-1261$

3) Saruchi, Kaith B.S., Kumar V., Jindal R., 2016. Biodegradation study of enzymatically catalyzed interpenetrating polymer network: evaluation of agrochemical release and impact on soil fertility, Biotechnol. Rep., 9, 74-81.

4) Mittal H., Alili A.A., Alhassan S.M., 2020. Solid polymer desiccants based on poly(acrylic acid-co-acrylamide) and laponite RD: Adsorption isotherm and kinetics studies, Colloids and Surfaces A. 599:124813

5) Mittal H., Kumar V., Alhassan S.M., Ray S.S., 2018. Modification of gum ghatti via grafting with acrylamide and analysis of its flocculation, adsorption and biodegradation properties. International journal of biological macromolecules, 114:283-294

6) Naushad M., ALOthman Z.A., 2015. Separation of toxic $\mathrm{Pb}^{2+}$ metal from aqueous solution using strongly acidic cation-exchange resin: analytical applications for the removal of metal ions from pharmaceutical formulation, Desalin. Water Treat. 53: 21582166. https://doi.org/10.1080/19443994.2013.862744. 
7) Mittal H., Alili A.A., Alhassan S.M., 2020. High efficiency removal of methylene blue dye using carrageenan-poly(acrylamide-co-methacrylic acid)/ AQSOA-Z05 zeolite hydrogel composites. Cellulose. 27: 8269-8285

8) Naushad M., Vasudevan S., Sharma G., Kumar A., Alothman ZA., 2016. Adsorption kinetics, isotherms, and thermodynamic studies for $\mathrm{Hg} 2+$ adsorption from aqueous medium using alizarin red-S-loaded amberlite IRA-400 resin, Desalination and Water Treatment 57 (39): 18551-18559. https://doi.org/10.1080/19443994.2015.1090914

9) Saruchi, Kaith B.S., Jindal R., Kapur G.S., 2013. Enzyme-based green approach for the synthesis of gum tragacanth and acrylic acid cross-linked hydrogel: its utilization in controlled fertilizer release and enhancement of water-holding capacity of soil. Iranian Polymer Journal. 22: 561-570.

10) Saruchi, Kaith B.S., Jindal R., Kapur G.S., Kumar V., 2014. Synthesis, characterization and evaluation of Gum tragacanth and acrylic acid hydrogel for sustained calcium chloride release-enhancement of water holding capacity of soil. Journal of the Chinese Advanced Materials Society. 2: 40-52

11) Saruchi, Kaith B.S., Jindal R., Vaneet K., 2015. Biodegradation of Gum tragacanth acrylic acid based hydrogel and its impact on soil fertility. Polymer Degradation and Stability. 115: 24-31.

12) Saruchi, Kaith B.S., Jindal R., Vaneet K., 2016. Biodegradation study of enzymatically catalyzed interpenetrating polymer network: evaluation of agrochemical release and impact on soil fertility. Biotechnology Reports. 9: 74-81.

13) Saruchi, Kumar V., 2019. Experimental Assessment of the utilization of the novel IPN in different processes in agricultural sector. Journal of Applied Polymer Science, 136 (28): $1-10$.

14) Saruchi, Kumar V., Mittal H., Alhassan S.M., 2019. Biodegradable Hydrogels of tragacanth gum polysaccharide to improve water retention capacity of soil and environment-friendly controlled release of agrochemicals. International Journal of Biological Macromolecules. 132, 1252-1261.

15) Ekebafe L.O., Ogbeifun D.E., Okieimen, F.E., 2011. Polymer Applications in Agriculture. Biokemistri. 23: $81-89$ 
16) Choudhary S., Jat A., Upadhyay P., Singh R., 2014. Hydrogel: the potentialities to produce more crops per drop in agriculture. Popular kheti. 2: 2321-0001

17) Alemzadeh I., Vossoughi M., 2007. Controlled release of paraquat from poly vinyl alcohol hydrogel. Chemical Engineering and Processing. 41: 707-710

18) Kulkarnia A., Soppimatha K., Aminabhavia T., Dave A., Mehta M., 2000. Glutaraldehyde crosslinked sodium alginate beads containing liquid pesticide for soil application. Journal of controlled release. 63: 97-105.

19) Vundavalli R., Vundavalli S., Nakka M., Rao S., 2015 Biodegradable nano-hydrogels in agricultural farming- alternative source for water resources. Procedia materials science. 10: $548-554$

20) Disha J., Begum M., Shawan M., Khatun N., Ahmed S., Islam M., Karim M., Islam M., Hossain M., Hasa M., 2016. Preparation and characterization of xanthan gum-based biodegradable polysaccharide hydrogels. Research journal of material sciences. 4: 13-18.

21) Jabrail F., Taraq A., Gupta K., 2018. Studies on preparation, characterization and biodegradation behaviour of HDPE natural polymers blends. Australian journal of basic and applied sciences. 12: 1-12

22) Montesanoa F., Parentea A., Santamariab P., Sanninoc A., Serio F., 2015. Biodegradable superabsorbent hydrogel increases water retention properties of growing media and plant growth. Agriculture and agricultural science procedia. 4: 451-458

23) Han H., Nam D., Seo D., Kim T., Shin B., 2004. Preparation and biodegradation of thermosensitive chitosan hydrogel as a function of $\mathrm{pH}$ and temperature. Macromolecular research. 12: 507-511

24) Guilherme M., Aouada F., Fajardo A., Martins A., Paulino A., Davi M., Rubira A., Muniz E., Marcos R., 2015. Superabsorbent hydrogels based on polysaccharides for application in agriculture as soil conditioner and nutrient carrier: a review. European polymer journal. 72: 365-385.

25) Cheng D., Liu Y., Yang G., Zhang A., 2018. Water and fertilizer-integrated hydrogel derived from the polymerization of acrylic acid and urea as a slow-release fertilizer and. Journal of agriculture and food chemistry. 66: 5762-5769 
26) Thakur S., Sharma B., Verma A., Chaudhary J., Tamulevicius S., Thakur V., 2018. Recent approaches in guar gum hydrogel synthesis for water purification. International Journal of Polymer Analysis and Characterization. 23: 621-632

27) Nagarjuna G., Babu P., Maruthi Y., Parandhama A., Madhavi C., Subha M., Rao K., 2016. Sodium alginate/tragacanth gum blend hydrogel membranes for controlled release of verapamil hydrochloric acid. Indian journal of Advances in Chemical Science. 4: 469477

28) Mittal H., Kumar V., Alhassan S., Ray S., 2018. Modification of gum ghatti via grafting with acrylamide and analysis of its flocculation, adsorption, and biodegradation properties. International journal of biological macromolecules. 114: 283-294

29) Hussein A., Khalil B., Abud H., 2017. Effect of crosslinking agent ratio and temperature on degree of swelling in polymer hydrogels. Chemical and process engineering research. 52: 2224

30) Kumar V., De D., Gupta A., 2015. Effect of ionic strength on swelling of gelatin hydrogel in marginal solvents. International journal of advance research in science and engineering. 4: 2319-2324

31) Kowalski G., Kijowska K., Witczak M., Kuterasiński L., Łukasiewicz M., 2019. Synthesis and effect of structure on swelling properties of hydrogels based on high methylated pectin and acrylic polymers. Polymers. 11: 114

32) Mittal H., Kumar V., Alhassan S., Ray S., 2018. Modification of gum ghatti via grafting with acrylamide and analysis of its flocculation, adsorption and biodegradation properties. International journal of biological macromolecules. 114: 283-294 
Figures

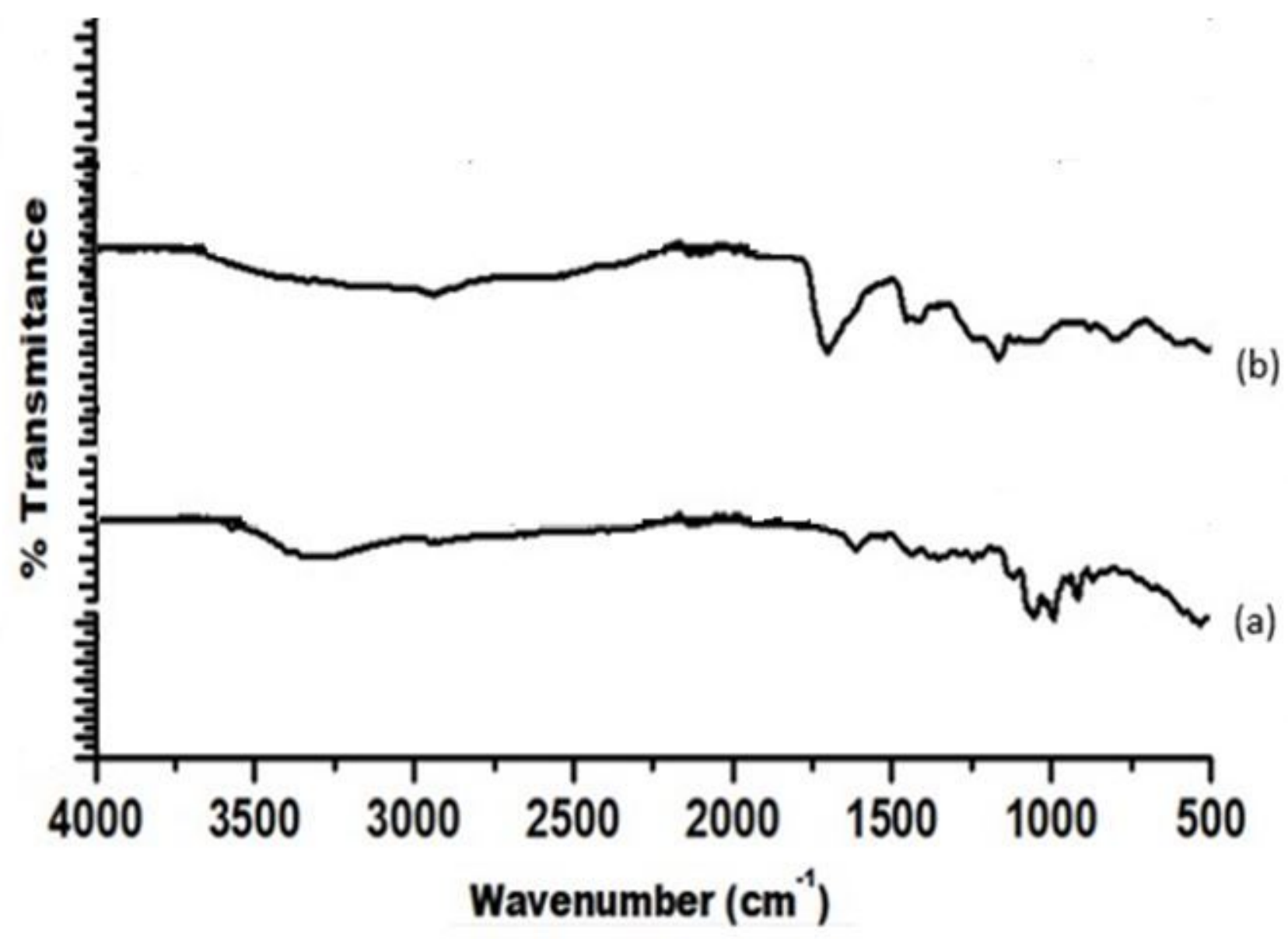

Figure 1

FTIR spectra of (a) Aloevera and (b) Av-cl-poly(AA) 

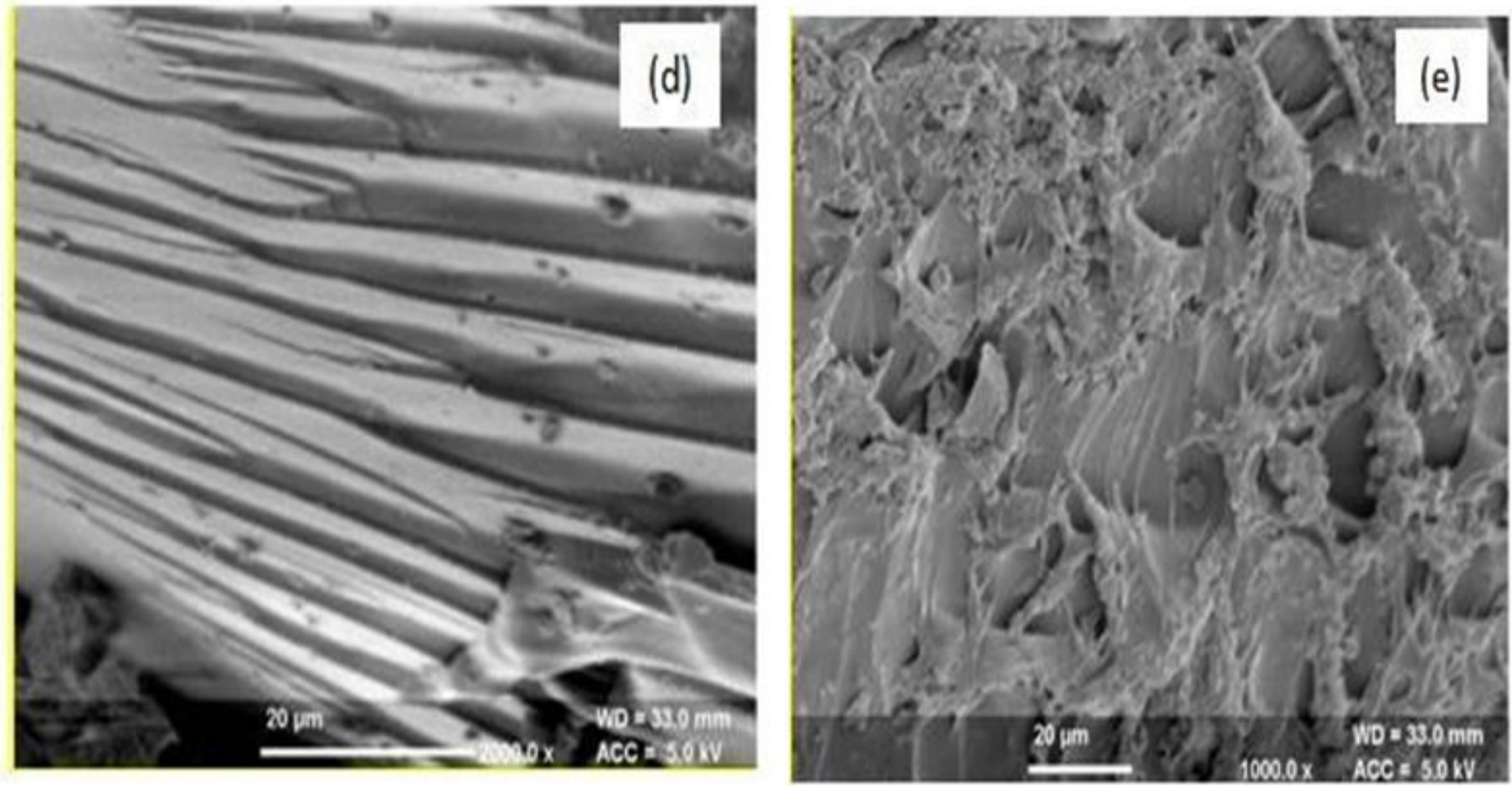

Figure 2

SEMs of (a) Aloe vera and (b) Av-cl-poly(AA)

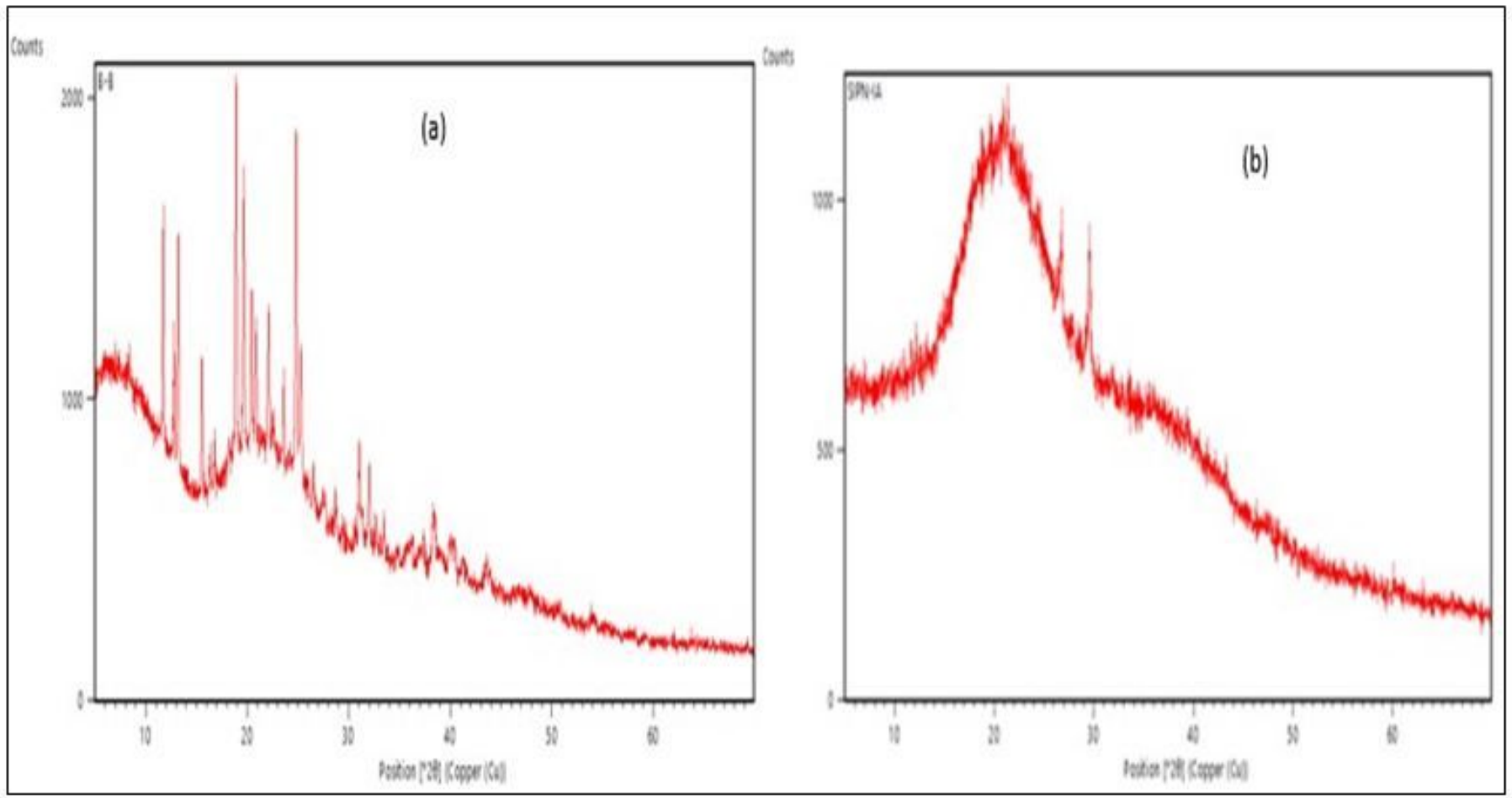

Figure 3

XRDs of (a) Aloevera and (b) Av-cl-poly(AA) 

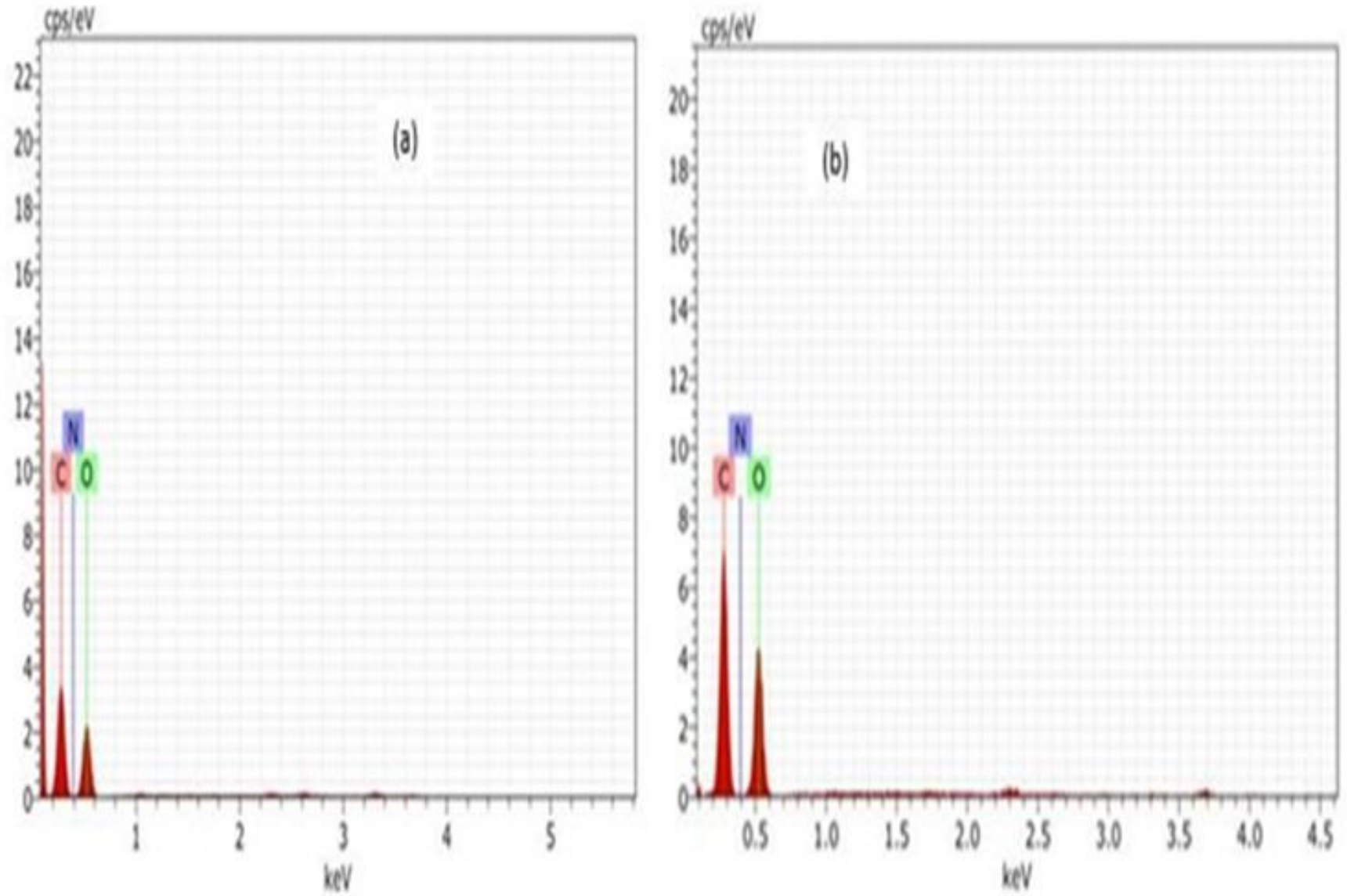

Figure 4

EDS of (a) Aloe vera and (b) Av-cl-poly(AA) 

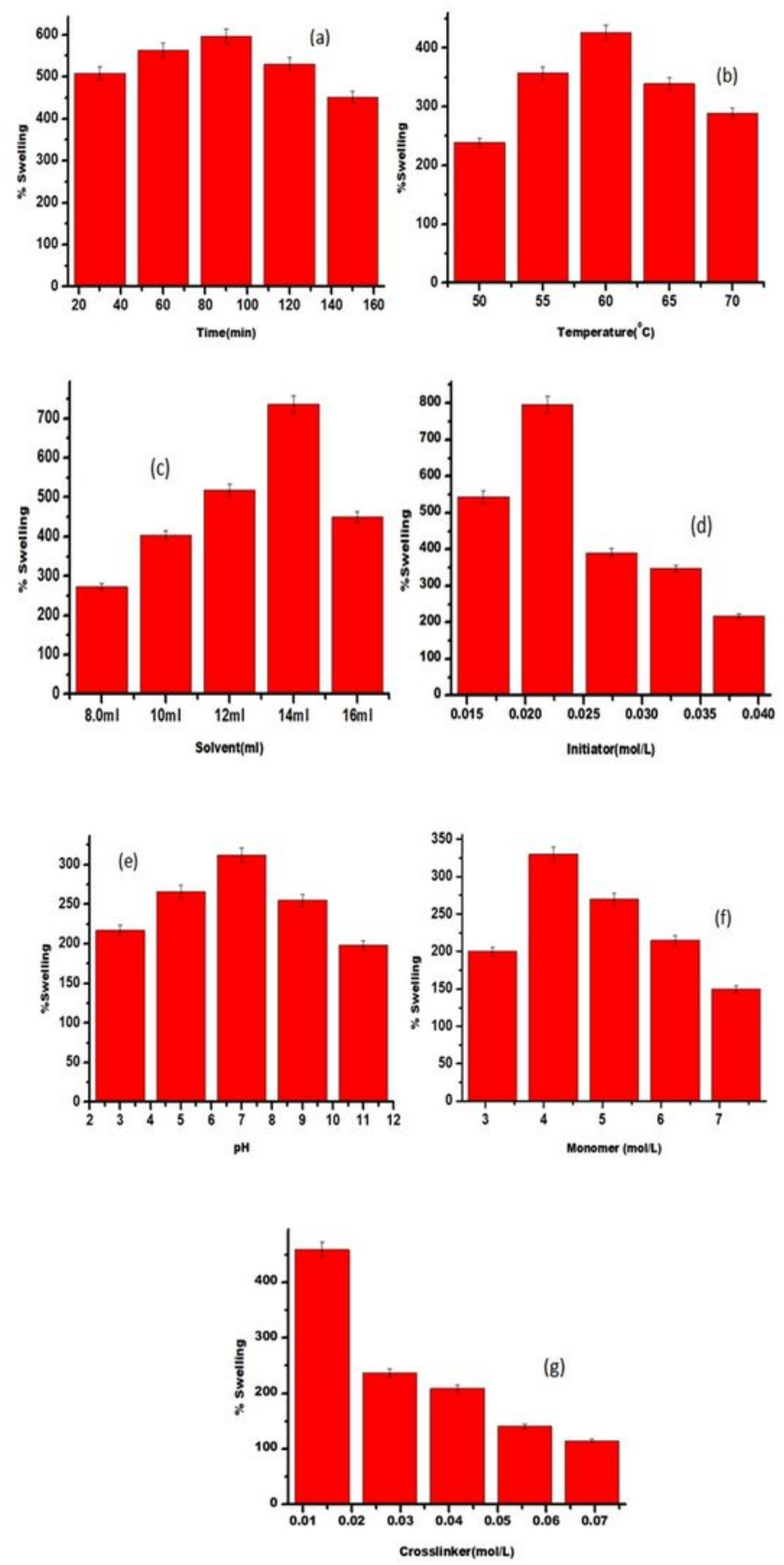

Figure 5

Impact of (a) time; (b) temperature; (c) solvent; (d) initiator concentration; (e) $\mathrm{pH}$; (f) monomer concentration and $(\mathrm{g})$ cross linker concentration on Ps of Av-cl-poly (AA) 

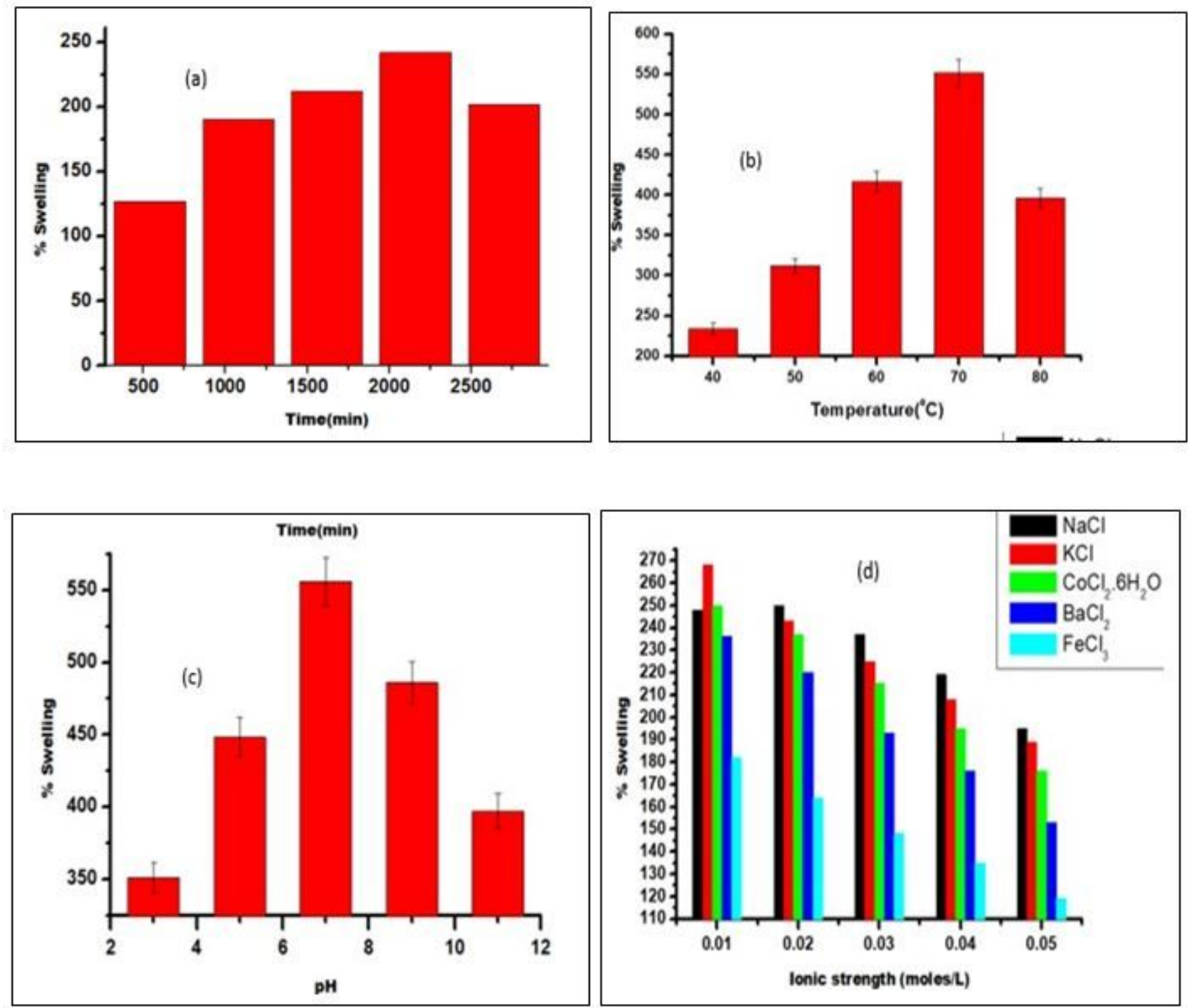

Figure 6

Impact of (a) time; (b) temperature; (c) pH; and (d) ionic strength on Ps of Av-cl-poly (AA) 


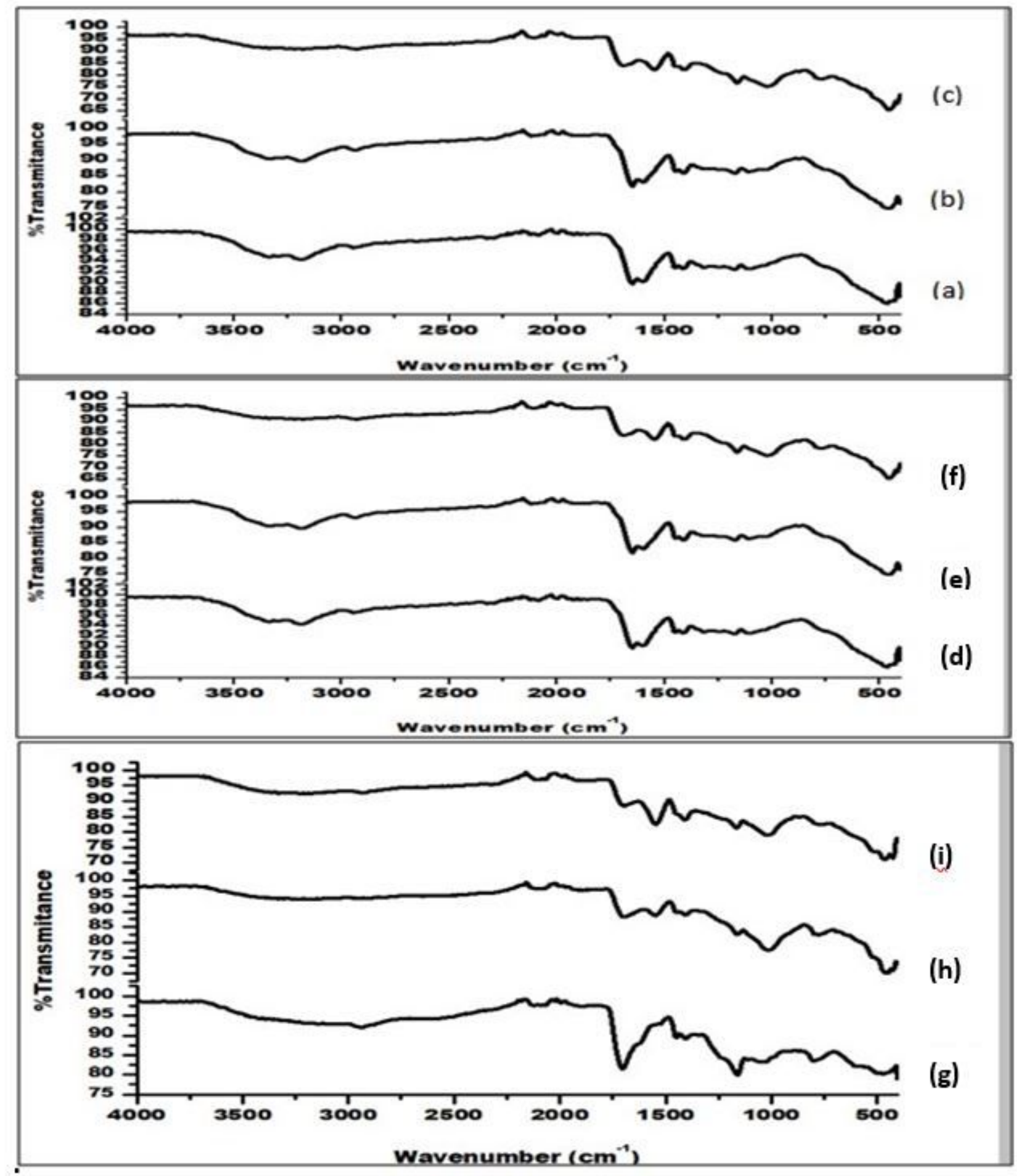

Figure 7

FTIR spectra of biodegradation of (a) Av-cl-poly(AA) stage-l; (b) Av-cl-poly(AA) stage-II and (c) Av-clpoly(AA) stage-III using soil burial method (d) Av-cl-poly(AA) stage-l; (e) Av-cl-poly(AA) stage-II and (f) Avcl-poly(AA) stage-IIl using composting method; (g) Av-cl-poly(AA) stage-l; (h) Av-cl-poly(AA) stage-Il; (i) Av-cl-poly(AA) stage-III using vermicomposting method 

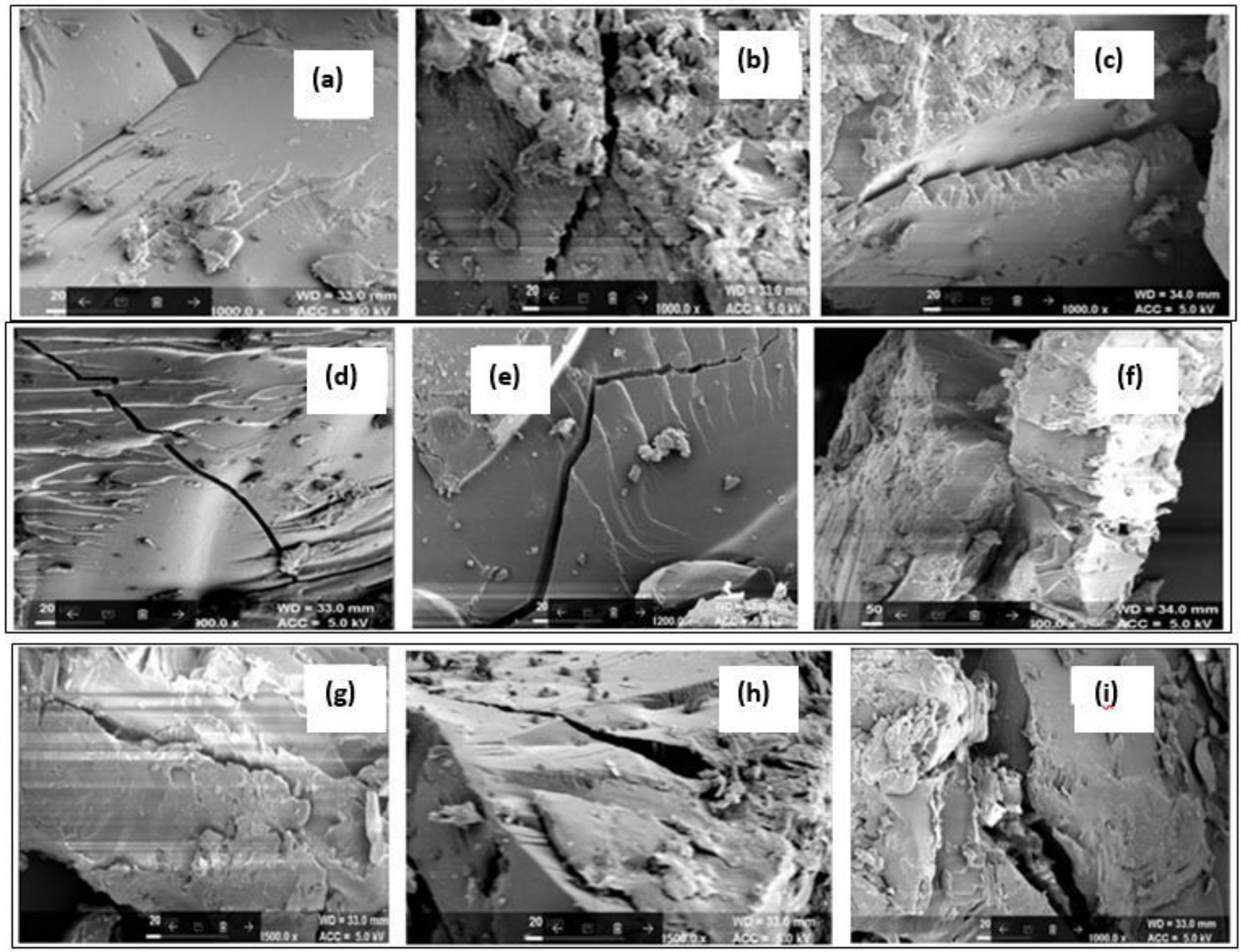

\section{Figure 8}

SEMs of biodegradation of (a) Av-cl-poly(AA) stage-l; (b) Av-cl-poly(AA) stage-Il and (c) Av-cl-poly(AA) stage-III using soil burial method (d) Av-cl-poly(AA) stage-l; (e) Av-cl-poly(AA) stage-II and (f) Av-clpoly(AA) stage-IIl using composting method; (g) Av-cl-poly(AA) stage-l; (h) Av-cl-poly(AA) stage-II; (i) Avcl-poly(AA) stage-III using vermi- composting method 

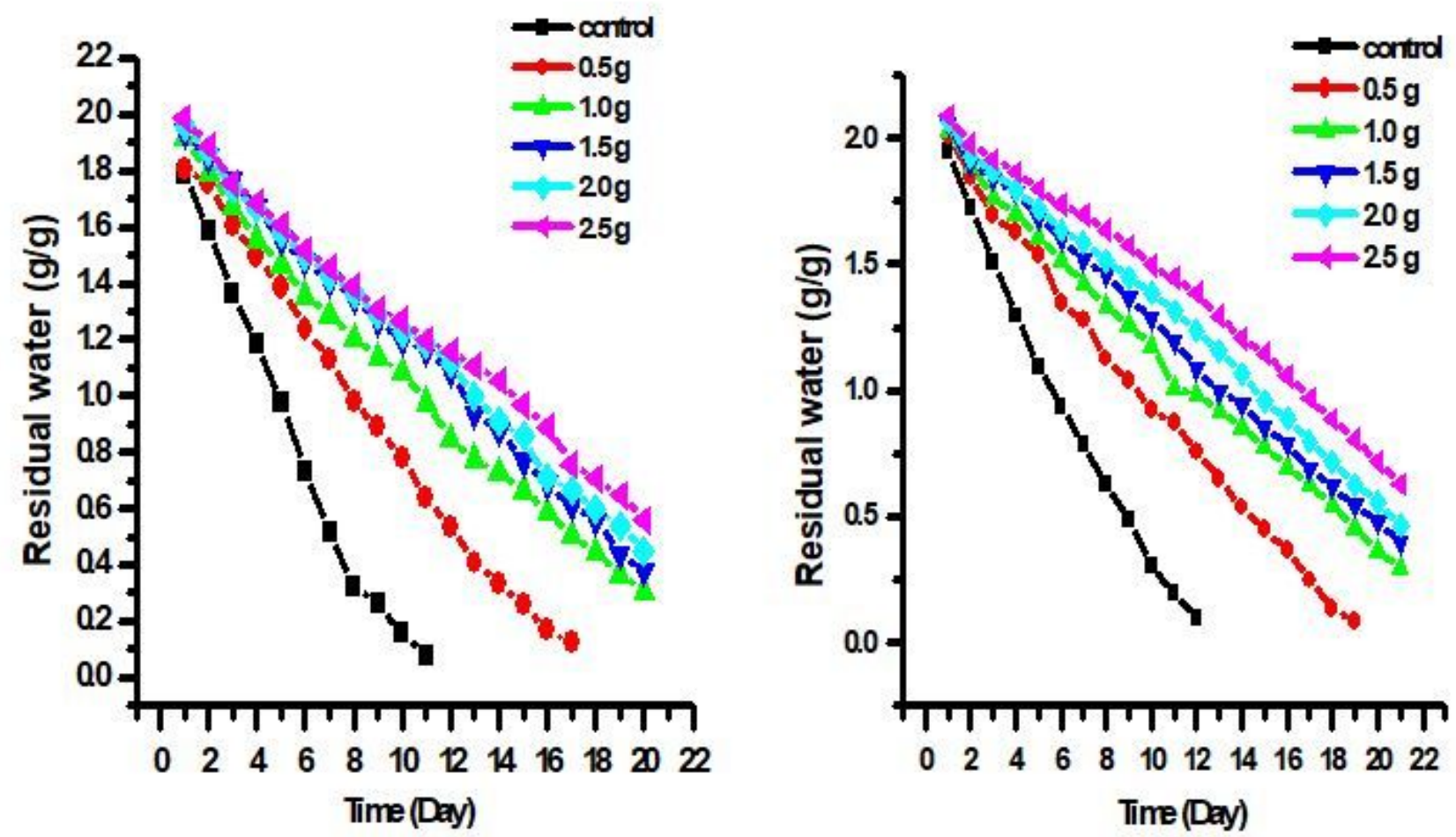

Figure 9

Water retention capacity of (a) clay soil and (b) sandy loam soil using Av-cl-poly(AA)
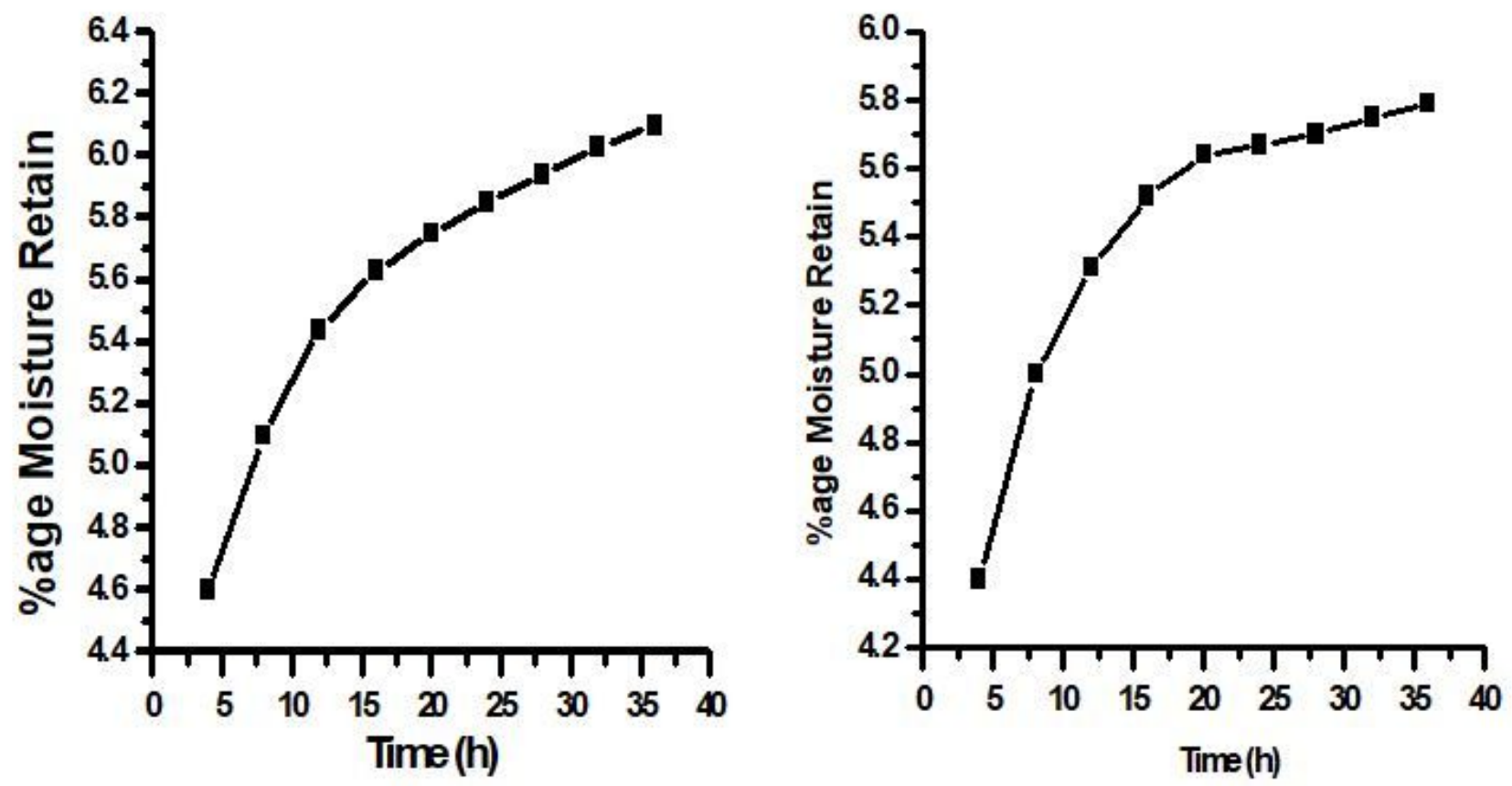
Figure 10

Water retention capacity of (a) clay soil and (b) sandy loam soil using Av-cl-poly(AA) 